BNL 50432

(Safeguards-Nuclear Materials Security - TID-4500)

UC.15

\title{
EFFECTS OF MEASUREMENT ERRORS ON LINEAR CALIBRATION EQUATIONS
}

\author{
Sylvester C. Suda and Donald F. Shepard*
}

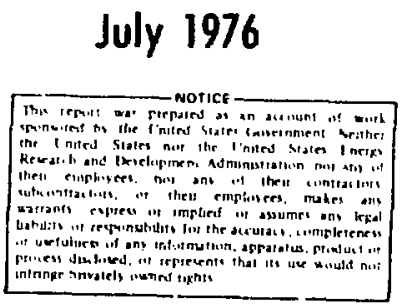

*Atlantic Richfield Hanford Company, Richlond, Woshington 99352

TECHNICAL SUPPORT ORGANIZATION DEPARTMENT OF APPLIED SCIENCE

BROOKHAVEN NATIONAL LABORATORY

UPTON, NEW YORK 11973 
NOTIC:

This report was prepared as an account of work sponowed by the Lnited stiters

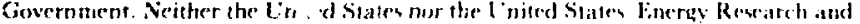

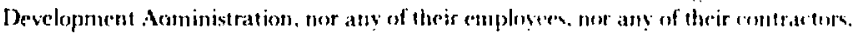

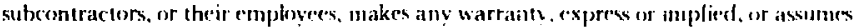

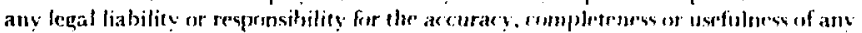
information, apparatus, prosluct or proceys diselesed. or reperesents 1 'at its use would nut infrimi, privitely anned rights.

Printed in the Lnited States of Anserica Avajlabje j̈rot

National Technical Information Service

L.S. Department of Commeres

5245 Port Reyal Road

Springfield, $V_{A} 22161$

Price: Printed Copy \$4.50: Microliche \$3.00

April 1977 515 copies 
This report sumbrizes the results of the developmental work in the area uf statistical treatment of calibration data performed in the preparation of American siatinal standard 315.19 . The affects or measuresent errors in both the dependent and independent variables in linear calibrations are studied by examining (l) a simulation model in witich the lat $n$ of $f$ it was zero with asingned known valies of the measuremert errors, (l) data from a laboratory calibrat ion af a processi vessel where the measurement urrors are small compared with the lack of $\mathrm{f} i \mathrm{t}$, (3) data from a process vessel cal braticn where the lack if fit dan he remeved through the use of a culite equation, and (4) data from a process vassel alibrition where the major error apgears to be in the dependent variable. The effert of meatsurement errors on the testimation of the standard feviation of the slope is found to be hifily dependent on the experimental desim used and an ibe subsequent treatment of the datis. 
CONTENTS

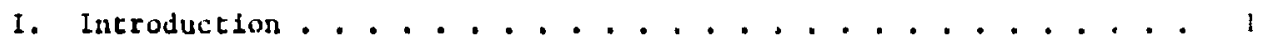

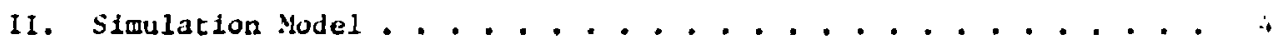

A. Example 1 - Simulated Data ................ 5

B. Analysis of simulated Data . . . . . . . . . . . 7

C. Results of Analysis. . . . . . . . . . . . . 10

111. Example 2 - Pressure Gauge Data. .............. 11

IV. Example 3 - Process Tank Data I. . . . . . . . . . . . Il)

V. Example 4 - Process Tank Data II ............. 31

VI. Analysis of Covariance . . . . . . . . . . . . . . it

VII. Adjustment of Data and the Analysis of Vartance. . . . . . . . it

A. Additional Discussion of Example 2........... 4 . .

B. Additional Discussion of Example 4... . . . . . . 44

VIII. Normalized Mean-Square Successive Differences. . . . . . . . I2

A. Additional Discussion of Example 3........... 55

IX. Sumnary. . . . . . . . . . . . . . . 55

x. References..................... . . . . . . . . 


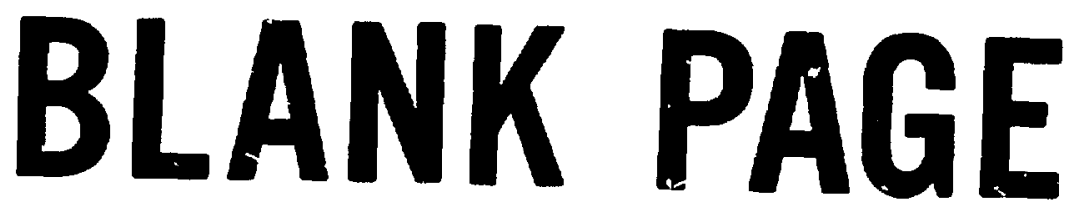


1. Scheme for numbering the sets. . . . . . . . . . . . . 5

2. Summary of simulated calibration . . . . . . . . . . . . g

3. Linear least-squares analysis - Example 2. . . . . . . . . 12

4. Estimates of coefficients and standard errors - Example 2. . . . 16

5. Analysis of covariance . . . . . . . . . . . . 16

6. One-way analysis of variance . . . . . . . . . . . . 17

7. Comparison of methods of analysis and standard deviations of the slope. . . . . . . . . . . . . . . . . . 19

8. Linear least-squares annlysis Example 3............ 21

9. Estimates of coefflcients and standard errors - Example 3. . . . 22

10. Analysis of covariance . . . . . . . . . . . . . . 22

11. Polynomial least-squares analysis. . . . . . . . . . . 25

12. Selected results of polynomial analysis. . . . . . . . . . 26

13. Two-crossed classification ANova of cubic iesldais. . . . . . 28

14. Analysis of polymonial fits to adjusted data . . . . . . . . 30

15. Analysis of variance of adjusted data. . . . . . . . . . 31

16. Linear Least-squares anaiysis - Example 4. . . . . . . . . . 32

17. Estimates of coefficients and standard ertors - Example ..... 36

18. Analysis of covariance . . . . . . . . . . . . . . 36

19. Estimates of coefficients and standard errors, Runs 1-3. . . . . 37

20. Analysis of covariance, Runs 1-3 . . . . . . . . . . 37

21. One-way analysis of variance, Runs 1-4............. 39

22. One-way analysis of variance, Runs 1-3..... . . . . . . . 40

23. Sumary of results of tests on Example 4........... 41

24. Algebralc notation.................. 43 
25. Brownlee's covariance table. . . . . . . . . . . . . 44

26. Computer worksheet - Lxample 2............... 50

27. Computer worksheet - Example 4 for $k=3$............ 53

\section{LIST OF FIGURES}

1. Destgn of simulated calibration experiment . . . . . . . . 6

2. Plot of residuals - Example 2................ 15

3. Plot of residuals about the adjusted least-squares 1ines . . . . 18

4. Plot of residuals for overall linear line - Example 3. . . . . 23

5. Plot of residuils for overall cubic line - Example 3... . . . 27

6. Plot of residuals for overall linear line - Example 4. . . . . 35

7. Plot of res'juals for overall quadratic line - Example 3..... 56 


\section{Effects of Measurement Errors on Linear Calibration Equations}

\section{INTRODUCTION}

The choice of an appropriate linear calibration model depends on a priori information regarding the nature of the measurement errors in the independent and dependent variables. However, the a priori information is not always available at the onset of 'ie calibration experiment, or the experimentor may have difficulty interpreting the information in terms of valfd statisticai analysis of the data. For example, in the analysis of tank callbration data it is usually assumed that the independent variable involved in the measurements based on standards or provers has negligible error. This is often the case, but by the nature of the experiment the determinations based on the provers are subject to cumulative fluctuations, and the possibility that these fluctuations may overshadow the independent errors in the dependest varlable must be kept in mind.

Let $x_{i}$ represent measurements of 1 iquid added to a tank and $y_{i}$ measurements of the height of liquid level. The fundamental relationship between the measured increments and the measured level is assumed to be

$$
y=a+b x
$$

where

$$
\begin{aligned}
& y=\text { measured level, } \\
& a=y \text { intercept, } \\
& b=\text { slope, and } \\
& x=Z x_{1}, \text { the sum of the measured increments. }
\end{aligned}
$$




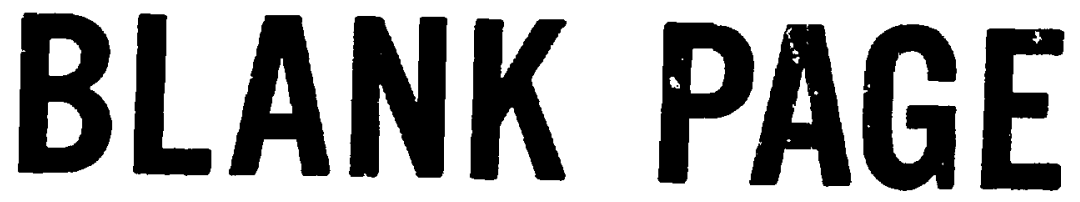


In the calibracion of a cank both $x_{i}$ and $y_{1}$ are sublect to measurement error. The tank is calibrated by adding measured quantities of liciuid to the tank and measuring the ligaid level. The $x$ vartable may be considered to be controlled since the quantities of liyuid are set at assigned values. For meir surements of special nuclear materlals the $x_{i}$ determinations must be based on precision provers whose calibrations are traceable to the Vational Bureau of Standards, and the $x_{i}$ measurements are therefore generally very accurate. liowever, the errors of the measured $x_{i}$ values, are cumulative. lirrors in $y_{i}$ are $a$ function of the sensing and response instruments. Typlcally, the larger urror is in the $y_{i}$ measurement.

Jaech $^{1}$ considers two cases of ficting straight lines to tank calluration data: the cumulative error model and the classical or independent error model. In the cumulative model the error of a siven point, $x=i x_{i}$, 1ncludes the wrors associated with all previous points anj tile dependent variable y is assumed to be measured wathout error. The classical model assumes that the independent variable $\boldsymbol{x}$ is measured without error. The appropriate model is the one whose uncerlying assumptions are more closely satisfied by what is known about the errors affecting the two variables.

The Important difference between the two models is in the estimate of the standard error of the slope. Mandel ${ }^{2 a}$ notes that the varlance estimate oi the slope given by using the indeyendent method where the cumulative model is appropriate results in a serious underestimation of the variance of the slope. This is a case where the smaller slope variance is not necessarily the "better" estimate. Mande $1^{2 b}$ further states that the lack of randomness in the residuals Indicates the presence of cumulative error in the data. On the basis of analy- 
sis at simulaced dild with cumulative error, the reliability of this randomness test lor diagrusin:, the presence of cundative error is questioned in this report.

like choice of mulel for fitting a straight line to tank callbration data should be basted on amalysis ol whith source of error is dominant. If the error in $x_{i}$ is dominant, the cumulative model is the appropriate one. If the $x_{i}$ are precise results or it the errurs in the determination of $x_{i}$ are considerabiy smaller than in the deternination of $y_{i}$, the classical model applies. The equation expressing errors assuciated with the calibration is

$$
y+e_{y}=a_{1}+b_{i}\left(x+e_{x}\right)+e_{t}
$$

wisere a anc $b$ are the intercept and slope, respectively, and

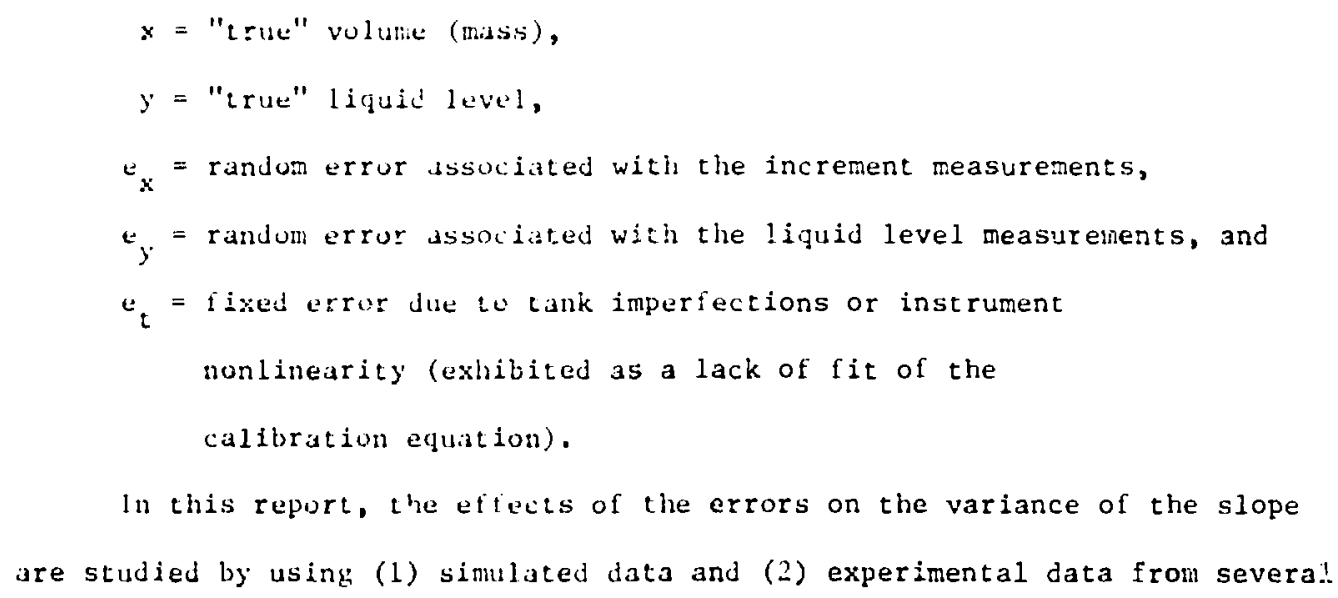

The increment measurements can be obtained using either gravimetri= or volumetric provers. In the examples that follow volumetric provers are assumed. 


\section{SIMULATION MODEL}

The effects of the error terms denoted by $\epsilon_{x}$ and $e_{y}$ in Eq. (2) on the standard error if the slope were studied by setting $e_{t}=0$ and using Monte Carlo techniques with the following simulation model:

$$
y_{i}=Y_{i}+e_{y}=-1.28+0.16 \sum\left(x_{i}+e_{x}\right)
$$

where

$$
\begin{aligned}
x_{i} & =100 \text { liters, } \\
Y_{i} & =\text { calculated iiquid level in centimeters, } \\
-1.28 & =\text { intercept } \\
0.16 & =\text { slope, } \\
e_{x} & =N(0,1) \sigma_{x}, \text { and } \\
e_{y} & =N(0,1) \sigma_{y} .
\end{aligned}
$$

The $N(0, i)$ are random normal deviates with mean zero and variance 1 . Observations of $e_{x}$ and $e_{y}$ were generated by multiplying values of $\sigma_{x}$ and $\sigma_{y}$, respectively, by randomly drawn normal deviates $\mathrm{N}(0,1)$.

Synthetic data for the measured volume, $x+e_{x}$, are calculated by adding values of $e_{x}$ to each $x$ increment of 100 liters. For each value $x_{i}=\Sigma\left(x_{i}+e_{x}\right)$, the value $Y_{i}=-1.28+0.16 \pi_{i}$ is calculated. Values for $e_{y}$ are calculated by using $\sigma_{y}$ and an obsurvation from $N(1,0)$. Values for the measured level response are $y_{i}=y_{i}+e_{y}$. The calibration experiment is simulated by carrying cut the

\footnotetext{
*An example of a process tank for which the relationship between the volume and the liquid-level height has a slope of 0.16 and $a$-intercept of -1.28 is a vertical right circular cylindrical tank with a radius of about 1.4 meters and an instrument heel of 8 liters.
} 
increment addition $n$ times. The resulting $n$ pairs of $x, y$ data points represent a callbration run.

Multiple realizations of the calibration experiment whth a given set of $\sigma_{x}$ and $\sigma_{y}$ values are observed by repeating the process with a different set of N $(0,1)$ deviates.

By varying the values of $\sigma_{x}$ and $\sigma_{y}$ and using the same sertes of $N(0,1)$ deviates, changes independent of the random effects in the standard error of the slope are observed.

A. Example 1 - Simulated Data

By using a wang $700 / 702$ computer and random normal devlates taken from. Natrella, ${ }^{3}$ Monte Carlo experiments were done ro simulate 304 calibration runs. The 304 runs consist of 19 sets of 16 runs; each run consists of 16 incremental additions. The same selection of $512 \mathrm{~N}(0,1)$ deviates was used for each rif tie 19 sets. The experimental design is shown in Figure 1, and the values of $\sigma_{x}$ and $\sigma_{y}$ are given in Table 1.

Table 1

Scheme for Numberiug the Sets

\begin{tabular}{lrrrr}
\hline & \multicolumn{5}{c}{$\sigma_{x}$, 1iters } \\
\cline { 2 - 5 }$\sigma_{y}, \cos$ & 0.16 & 0.08 & 0.04 & 0.0 \\
\hline 0.00 & 1 & 2 & 3 & - \\
0.02 & 4 & 6 & 9 & 19 \\
0.04 & 5 & 8 & 12 & 18 \\
0.08 & 7 & 11 & 14 & 17 \\
0.16 & 10 & 13 & 15 & 16 \\
\hline
\end{tabular}




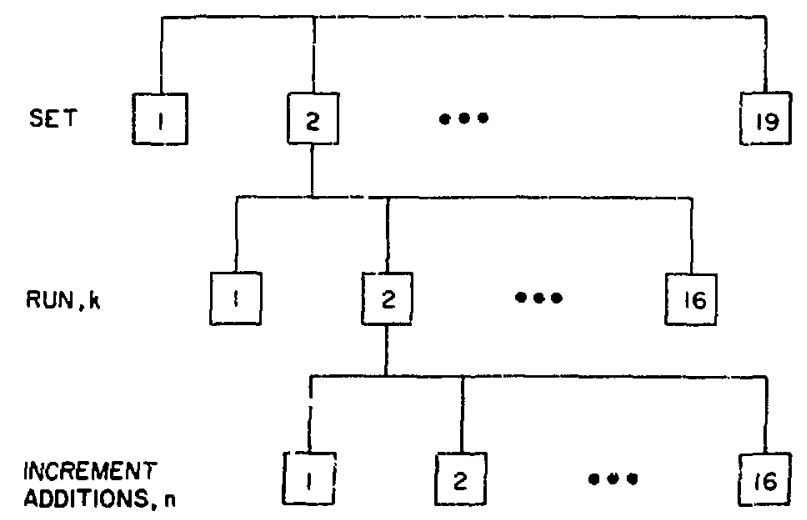

Figure 1. Design of simulated calibration experiment. 
Sixteen 100-liter increments were used to generate a calibral on ru.: Each increment of 100 liters (observed $x$ value) was adjusted to its simulated value by adding a correction of $e_{x}$ obtalied by multiplying a $N(0,1)$ deviate by the appropriate value of $\sigma_{x}$. By using Eq. (3) the "stmulated" value of $Y$ in centimeters was calculated and adjusted by $e_{y}$ to 1 ts observed value of $y$, with $e_{y}$ obtained in the same manner as $e_{x}$. The resulting 16 pairs of $x$, $y$ data points ware fitted by using the independent model.

B. Analysis of Simulated Data

The data were analyzed by using the $F$ test of the ratios of percent error of the slope, by analysis of covariance, and by use of the normalized meansquare successive difference (u) t.sst.

The percent error $P_{i}$ of each observed slope was calculated:

$$
p_{i}=100\left(b_{i}-0.16\right) / 0.16
$$

The observed standard deviation of the percent elror of the slope for a set of if runs is

$$
\text { cbs \% S.D. }=\left[\Sigma\left(P_{i}-\bar{P}\right)^{2} / 15 j^{1 / 2}\right.
$$

The calculated standard deviation of the percent error of the slope for a set was obtalned by averaging the 16 values of the variance of the slope and multiplying this result by 100 :

$$
\text { calc. \% S.D. }=(100 / 0.16)\left[\Sigma \hat{V}\left(b_{i}\right) / 16\right]^{1 / 2} \text {. }
$$


Ratios of the observed to calculated standard deviation of the percent error in the slope for the 19 sets are presented in part 1 of Table 2. Tho obs/calc variance ratios are $F$ distributed with 15 and 224 degrees of $f$ reedom. The critical value for $F[\alpha=0.05(15,224)]$ is 1.67 .

The 16 calibration runs per set were grouped in the order they were generated into 4 quartets of 4 runs each, and each quartet was exanined by the anilysis of covariance described by $3 r o w n l e e^{4 a}$ and in Section VI of this report. Ratios of the mean squares for the variance between the individual slopes, $s_{2}{ }^{2}$, and for the deviation of the group means, $\mathrm{s}_{3}{ }^{2}$, to the mean square about the individual lines $\mathrm{s}_{1}{ }^{2}$, were calculated. The ratios, $\mathrm{s}_{2}{ }^{2} / \mathrm{s}_{1}{ }^{2}$, are $\mathrm{F}$ distributed with 3 and 15 degrees of freedom. At a significance level of $a=0.05$, the number of quartets pe: set in which the hypothesis of consistency between the four runs was rejected was noted. The results are sumarized in part 2 of Table 2.

The third lest of the data was the normalized mean-square successive difference (u) test, the basis for which is explained in Section VII.

The statistic $u$ is approximately $\mathrm{N}(0,1)$ distributed for $\mathrm{n}$ as small as 10 . The regions of interest are as follows:

$u=2$, which indicates that the $y$ variate is not normally distributed (e.g., because of rounding or transcription error);

$-2<u<2$, the region of nonrejection; and

$u<-2$, which indicates that the dominant error is in the $x$ variate (volume measurement) since $e_{t}=0$.

The numbers of runs per set rajected on the basis of the above criteria are presented in part 3 of Table 2. 


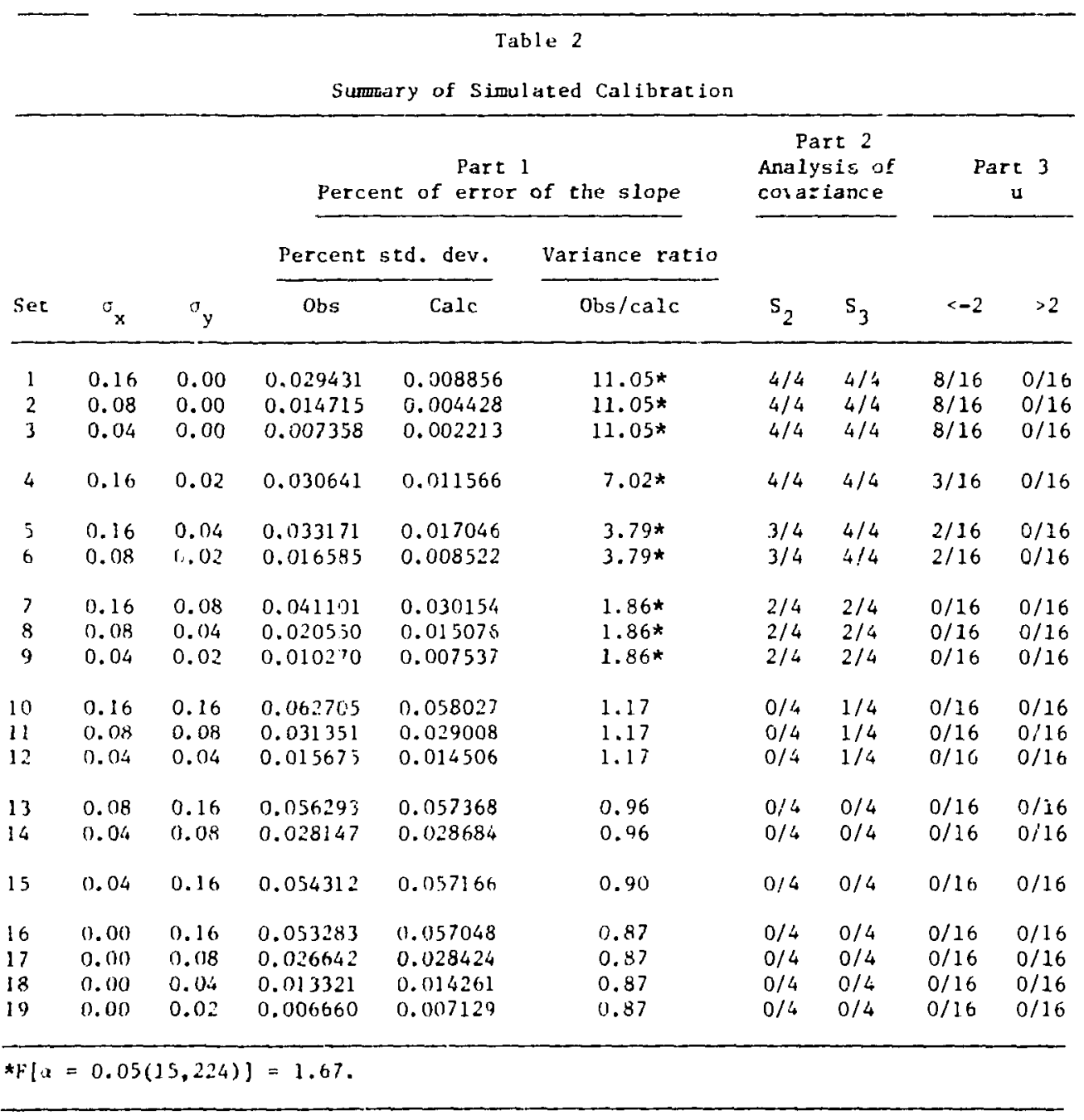




\section{c. Results of Analysis}

This example 1llustrates the effects of cumulative error on the est inated variance of the slope. Table 2 shows that three tests for sets 1 through 6 are significant at the $5 \%$ level. In this example, the variance ratio test of percent error of the slope and the analysis of zovariance are based on 14 and 224 degrees of freedom and is a more sensitive Indicator of cumulative error in the independent variable than is the u test, which is the test applied to a single run having 14 degrees of freedom.

To the practitioner, Table 2 indicates that the use of prectsion provers in the calibration of tanks would permit use of the Independent error model without resulting in serfous underestimation of the variance of the slope. Typically the standard deviation, $\sigma_{x}$, of a 100-1iter prover is in the range of 0.0075 liters. The standard deviation, $\sigma_{y}$, of the liquid-level sensor and response system is 0.02 centimeters.

The effect of $\sigma_{x}$ and $\sigma_{y}$ on the observed and calculated percent variances of the slope appear to be additive. From the data in part 1 of Table 2 the standard deviation for $\sigma_{x}=0.16, \sigma_{y}=0.16$ (set 10) can be estimated by adding the variance of sets 1 and 16. Since in most tank calibrations the value of $\sigma_{x}$ is well known from calibration of the prover, the underestimation of the slope varlance by the independent error model can be estimated.

The estimation procedure involves use of the calculated standard deviation of the slope obtained by the independent model and the $\sigma_{x}$ value from calibration of the prover. For example, for $\sigma_{x}=0.16$ and $\sigma_{y}=0.04$, the calculated S.D. (b) is 0.017046 . By using data from part 1 of Table 2 , a reasonable estimate of the observed S.D. (b) $=0.033171$ can be determined: 


$$
\left[(0.017046)^{2}-(0.008856)^{2}+(0.0: 9431)^{2}\right]^{1 / 2}=0.032838
$$

The above computations and evaluations are instructive and are suggested practice for the preliminary analysis of tank calibration data.

\section{EXAMPLE 2 - PRESSURE GAUGE DATA}

This example, from data supplied by Schooner and Houser, ${ }^{5}$ illustrates the case in which the measurement errors $e_{x}$ and $e_{y}$ in Eq. (2) are small compared with $e_{t}$, which is the lack of fit due to nonuniformity of the tank diameter or nonlinearity of the device used to measure the y variate.

The experiment was done with a right circular cylindrical tank and a Ruska $X R-38$ pressure counter. The calibration increments were measured with 30-gallon and 100-gallon provers. Data from the first 6 runs, made under wetwall conditions, were fitted with stralght lines by the independent error model. Data for the 6 runs along with the predicted values of $y$ and residual $y$ are listed in Table 3.

Also listed in Table 3 are values of $R_{n}$, the statistic used by Tietjen et $a 1 .{ }^{6}$ to detect a single outlier; for a sample size of 9 and $\alpha=0.05$ the critical value is 2.28. The values of predicted and residual $x$ are useful for checking for data recording errors and for developing some idea of the magnitude of the error associated with the use of Eq. (1).

Graphical or statistical analysis of the residuals is indispensable to any situation--1inear, polynomial, nonlinear, or analysis of variance--where a model is fitted. The examination of residuals is a necessary first step in testing the validity of the underlying least-squares model and is an important 
Table 3

Linear least-Squares Analysis - Example 2

\begin{tabular}{|c|c|c|c|c|c|c|c|c|}
\hline $\begin{array}{l}\text { PC. } \\
\text { No. }\end{array}$ & $\begin{array}{l}\text { Obs } \\
\mathbf{x}\end{array}$ & $\begin{array}{c}\text { Obs } \\
y\end{array}$ & $\begin{array}{c}\text { Pred. } \\
y\end{array}$ & $\underset{y}{\operatorname{Res} 1 \mathrm{~d}}$ & $\begin{array}{l}\text { Cusum } \\
\text { resid. }\end{array}$ & $R_{n}$ & $\begin{array}{c}\text { Pred. } \\
x\end{array}$ & $\begin{array}{l}\text { Resid. } \\
\mathbf{x}\end{array}$ \\
\hline \multicolumn{9}{|c|}{ Run 1} \\
\hline 1 & 113.534 & .2 .531 & 2.600 & .069 & .069 & 1.558 & 112.751 & -.782 \\
\hline 2 & 492.136 & 36.062 & 36.008 & -.053 & .015 & 1.100 & 492.738 & .602 \\
\hline 3 & 870.744 & 69.387 & 69.418 & .031 & .047 & .610 & 870.391 & -.352 \\
\hline 4 & 1249.298 & 102.840 & 102.822 & -.017 & .029 & .331 & 1249.495 & .197 \\
\hline 5 & 1627.960 & 136.257 & 136.236 & -.020 & .009 & .384 & 1628.190 & .230 \\
\hline 6 & 2006.570 & 169.662 & 169.646 & -.015 & -.006 & .303 & 2006.750 & .180 \\
\hline 7 & 2385.145 & 203.134 & 203.052 & -.081 & -.088 & 1.600 & 2386.069 & .924 \\
\hline 8 & 2763.714 & 236.446 & 236.458 & .012 & -.075 & .253 & 2763.575 & -.138 \\
\hline 9 & 3142.293 & 269.789 & 269.864 & .075 & .000 & 1.713 & 3141.432 & -.860 \\
\hline \multicolumn{9}{|c|}{ Run 2} \\
\hline 1 & 113.601 & 2.540 & 2.614 & .074 & .074 & 1.601 & 112.756 & -.844 \\
\hline 2 & 492.144 & 36.070 & 36.016 & -.053 & .021 & 1.049 & 492.746 & .602 \\
\hline 3 & 870.714 & 69.390 & 69.421 & .031 & .052 & .590 & 870.356 & -.357 \\
\hline 4 & 1249.289 & 102.848 & 102.826 & -.021 & .031 & .385 & 1249.529 & .240 \\
\hline 5 & 1627.871 & 136.258 & 136.232 & -.025 & .006 & .457 & 1628.159 & .288 \\
\hline 6 & 2006.624 & 169.671 & 169.653 & -.017 & -.011 & .319 & 2006.823 & .199 \\
\hline 7 & 2385.277 & 203.147 & 203.065 & -.081 & -.092 & 1.524 & 2386.200 & .923 \\
\hline 8 & 2763.702 & 236.447 & 236.457 & .010 & -.082 & .206 & 2763.583 & -.118 \\
\hline 9 & 3142.218 & 269.775 & 269.857 & .082 & .000 & 1.772 & 3141.284 & -.933 \\
\hline \multicolumn{9}{|c|}{ Run 3} \\
\hline 1 & 113.592 & 2.537 & 2.607 & .070 & .070 & 1.569 & 112.792 & -.799 \\
\hline 2 & 492.217 & 36.072 & 36.018 & -.053 & .017 & 1.093 & 492.823 & .606 \\
\hline 3 & 870.771 & 69.393 & 69.423 & .030 & .047 & .584 & 870.429 & -.341 \\
\hline 4 & 1249.325 & 102.846 & 102.827 & -.018 & .029 & .341 & 1249.530 & .205 \\
\hline 5 & 1627.933 & 136.258 & 136.237 & -.020 & .008 & .385 & 1628.167 & .234 \\
\hline 6 & 2007.418 & 169.650 & 169.635 & -.014 & -.005 & .265 & 2006.577 & .159 \\
\hline 7 & 2384.969 & 203.123 & 203.040 & -.082 & -.088 & 1.601 & 2385.906 & .937 \\
\hline 8 & 2763.554 & 236.437 & 236.447 & .010 & -.077 & .219 & 2763.432 & -.121 \\
\hline 9 & 3142.055 & 269.770 & 269.847 & .077 & .000 & 1.730 & 3141.173 & -.881 \\
\hline \multicolumn{9}{|c|}{ Run 4} \\
\hline 1 & 113.553 & 2.534 & 2.609 & .075 & .075 & 1.638 & 112.702 & -.850 \\
\hline 2 & 492.086 & 36.065 & 36.009 & -.055 & .019 & 1.109 & 492.713 & .627 \\
\hline 3 & 870.689 & 69.388 & 69.416 & .028 & .047 & .537 & 870.368 & -.320 \\
\hline 4 & 1249.254 & 102.838 & 102.819 & -.018 & .029 & .338 & 1249.461 & .207 \\
\hline 5 & 1627.794 & 136.243 & 136.220 & -.022 & .007 & .405 & 1628.045 & .251 \\
\hline 6 & 2006.368 & 169.642 & 169.624 & -.017 & -.009 & .314 & 2006.561 & .193 \\
\hline 7 & 2384.997 & 203.115 & 203.033 & -.081 & -.090 & 1.538 & 2385.915 & .918 \\
\hline 8 & 2763.698 & 236.438 & 236.449 & .011 & -.079 & .226 & 2763.569 & -.128 \\
\hline 9 & 3142.226 & 269.770 & 269.849 & .079 & .000 & 1.732 & 3141.326 & -.899 \\
\hline
\end{tabular}




\begin{tabular}{|c|c|c|c|c|c|c|c|c|}
\hline $\begin{array}{l}\mathrm{Pt} \text {. } \\
\text { No. }\end{array}$ & $\begin{array}{c}\text { Obs } \\
x\end{array}$ & $\begin{array}{c}\text { Obs } \\
y\end{array}$ & $\begin{array}{c}\text { Pred. } \\
y\end{array}$ & $\begin{array}{c}\text { Resid. } \\
y\end{array}$ & $\begin{array}{l}\text { Cusum } \\
\text { resid. }\end{array}$ & $R_{n}$ & $\begin{array}{l}\text { Pred } \\
\qquad x\end{array}$ & $\begin{array}{c}\text { Restd. } \\
x\end{array}$ \\
\hline \multicolumn{9}{|c|}{ Run 5} \\
\hline 1 & 113.594 & 2.535 & 2.605 & .070 & .070 & 1.647 & 112.794 & -.799 \\
\hline 2 & 492.222 & 36.068 & 36.015 & -.052 & .018 & 1.119 & 492.814 & .592 \\
\hline 3 & 870.806 & 69.396 & 69.422 & .026 & .044 & .528 & 870.511 & -.292 \\
\hline 4 & 1249.172 & 102.826 & 102.809 & -.016 & .027 & .333 & 1249.363 & .191 \\
\hline 5 & 1627.667 & 136.227 & 130.207 & -.019 & .007 & .380 & 1627.887 & .220 \\
\hline 6 & 2006.167 & 169.624 & 169.606 & -.017 & -.009 & .347 & 2006.366 & .199 \\
\hline 7 & 2384.500 & 203.067 & 202.990 & -.076 & -.086 & 1.552 & 2385.366 & .866 \\
\hline 8 & 2763.548 & 236.42 .4 & $236.43 i$ & .013 & -.072 & .295 & 2763.391 & -.156 \\
\hline 9 & 3142.045 & 269.764 & 269.836 & .072 & .000 & 1.690 & 3141.224 & -.820 \\
\hline \multicolumn{9}{|c|}{ Run 6} \\
\hline 1 & 113.616 & 2.541 & 2.617 & .076 & .076 & 1.663 & 112.745 & -.870 \\
\hline 2 & 492.137 & 36.070 & 36.018 & -.051 & .025 & 1.023 & 492.721 & .584 \\
\hline 3 & 870.670 & 69.395 & 69.420 & .025 & .050 & .473 & 870.385 & -.284 \\
\hline 4 & 1249.170 & 102.839 & 102.818 & -.020 & .030 & .367 & 1249.397 & .227 \\
\hline 5 & 1627.721 & $136.24 \%$ & 136.222 & -.024 & .005 & .449 & 1628.002 & .281 \\
\hline 6 & 2006.198 & 169.637 & 169.618 & -.018 & -.012 & .330 & 2006.403 & .205 \\
\hline 7 & 2384.765 & 203.105 & 203.023 & -.081 & -.094 & 1.533 & 2385.687 & .922 \\
\hline 8 & 2763.309 & 236.414 & 236.426 & .012 & -.081 & .242 & 2763.170 & -.138 \\
\hline 9 & 3141.909 & 269.752 & 269.833 & .081 & .000 & 1.770 & 3140.981 & -.927 \\
\hline
\end{tabular}


supplement to other diagnostic techniques in ldentifying causes of abnormalltes in data.

The residuals for the 6 calibration runs were plotted against the volume values (Figure 2), and the plots were examined for trends and scatter. Two things are evident: (a) individual observations are closely grouped about 9 calibration points, and (b) the calibration points display erratic swings that are large compared with the measurement error. This Indicates the presence of error associated with $e_{t}$ defined in Eq. (2).

The estimates of the coefflcients and the standard errors of the coefficlents for the 6 ruis are shown in Table 4. The estimates for the overall least-squares line are given in the line labeled "Sum." The u test statistic Is defined in section VIII.

In the analysis of covariance given In Table 5, the F ratios are all abnorma11y low. The $F$ ratio of the mean square due to the differences of the individual slopes compared with the mean square of the points about the individual lines is significantly low at the $\alpha=0.001$ level.

The plot of the residuals and the analysis of covariance suggest that, instead of six Independent estimates of the regression line, the data constst of six replicate observations of $y_{j i}$ at each of the nine $\bar{x}_{1}$ values. One method of treating such data is to adjust values of the dependent varlable to take account of differences among the associated values of the Independent variable. To eliminate the small effect of the observed differences in the $x_{j i}$ values, the $y_{j i}$ values in each 1 cluster were adjusted to the same $\bar{x}_{1}$ value by the method described in Section VII.

The $\bar{x}$ values and the adjusted $y$ values (denoted by $y^{\prime}$ ) are listed in Table 6 . 


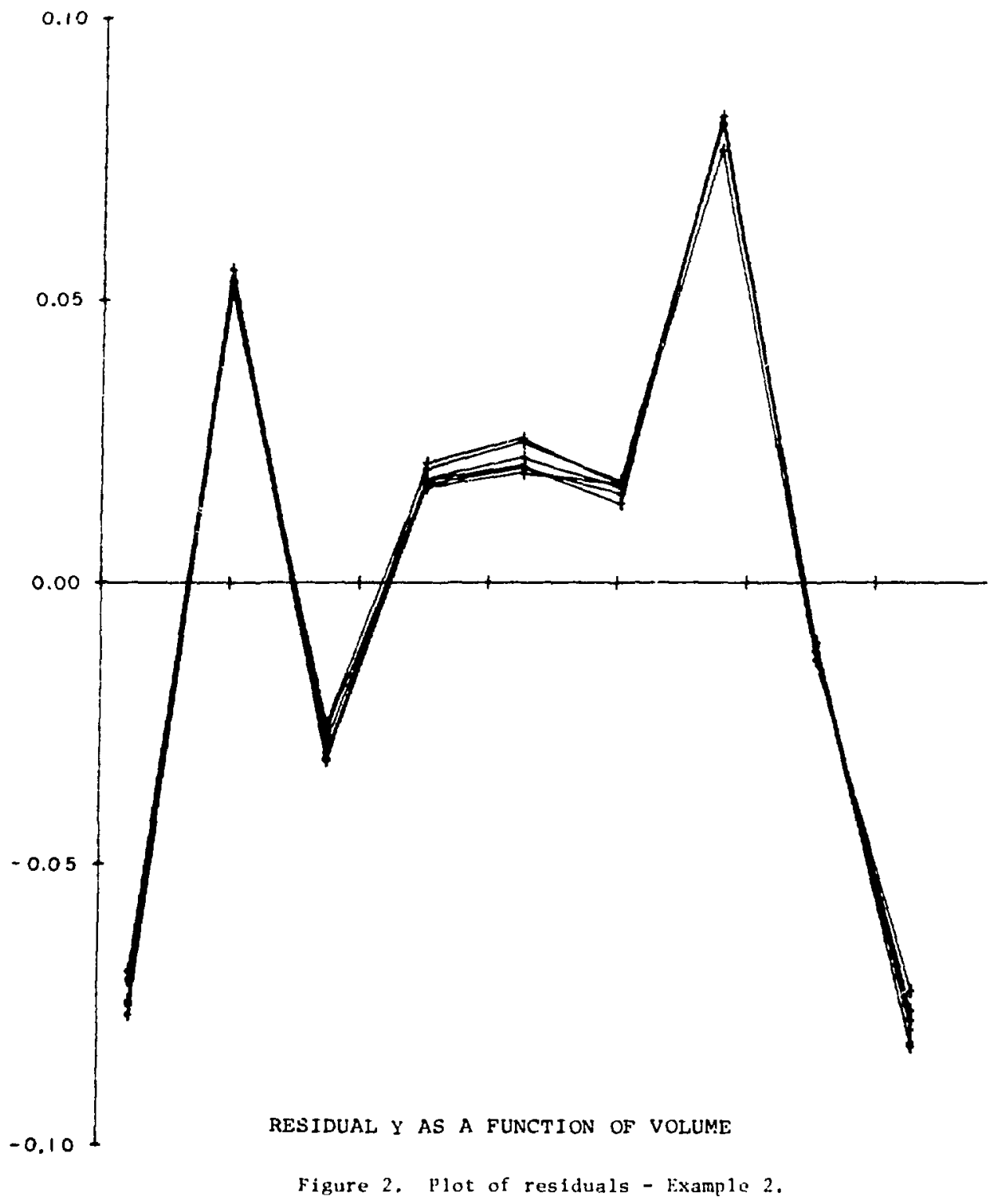


Jable 4

st Imates of Coefflelerts and Standard Errors - Example 2

\begin{tabular}{|c|c|c|c|c|c|c|}
\hline k & $\mathbf{a}$ & b & $\begin{array}{l}\text { St d. dev. } \\
\text { y resld. }\end{array}$ & $\operatorname{ard}_{a}^{\text {stdev. }}$ & Std. dev. & $u$ \\
\hline 1 & -7.41842171 & .08824237 & .05620650 & .03639405 & .000019166 & -.1924 \\
\hline 2 & -7.40958362 & .08823926 & .05894573 & .03816810 & .000020100 & -.3050 \\
\hline 3 & -7.41615726 & .08824285 & .05695022 & .03687755 & .000029421 & -.1931 \\
\hline 4 & -7.41048219 & .08823676 & .05809622 & .03761699 & .000019810 & -.2567 \\
\hline 5 & -7.41799587 & .08824010 & .05429956 & .03516053 & .000018518 & -.2485 \\
\hline 6 & -7.40760725 & .08823979 & .05857229 & .03792 .713 & .000019976 & -.4000 \\
\hline Sum & $-7.413374 ; 3$ & .08824019 & .05156269 & .01363050 & $.00000: 178$ & -.6461 \\
\hline $\bar{x}, \bar{y}$ & -7.41337507 & .08824019 & .05714730 & .03700392 & .00001 .9288 & -.2672 \\
\hline
\end{tabular}

Table 5

Analysis of Covarlance

\begin{tabular}{|c|c|c|c|c|}
\hline Source of variance & $\begin{array}{l}\text { Sum of } \\
\text { squares }\end{array}$ & $\begin{array}{l}\text { Degrees } \\
\quad \text { of } \\
\text { Ereedom }\end{array}$ & $\begin{array}{c}\text { Mean } \\
\text { square }\end{array}$ & $\begin{array}{c}F \\
\text { rat } 10\end{array}$ \\
\hline $\begin{array}{l}\text { Between } \hat{b} \text { and } \bar{b} \\
\text { Deviations of group } \\
\text { means about their }\end{array}$ & .000000889 & 1 & .000000889 & .00027 \\
\hline least-squares line & .000593510 & 4 & .000148377 & .04534 \\
\hline $\begin{array}{l}\text { Between individual slopes } \\
\text { Deviations of individual } \\
\text { points about their }\end{array}$ & .000226000 & 5 & .000045200 & .01381 \\
\hline least-squares IInes & .137433000 & 42 & .003272214 & \\
\hline About over all line & .138254000 & 52 & .002658730 & \\
\hline Due to overall line & 401717.70784600 .0 & 1 & 401717.707846000 & \\
\hline
\end{tabular}




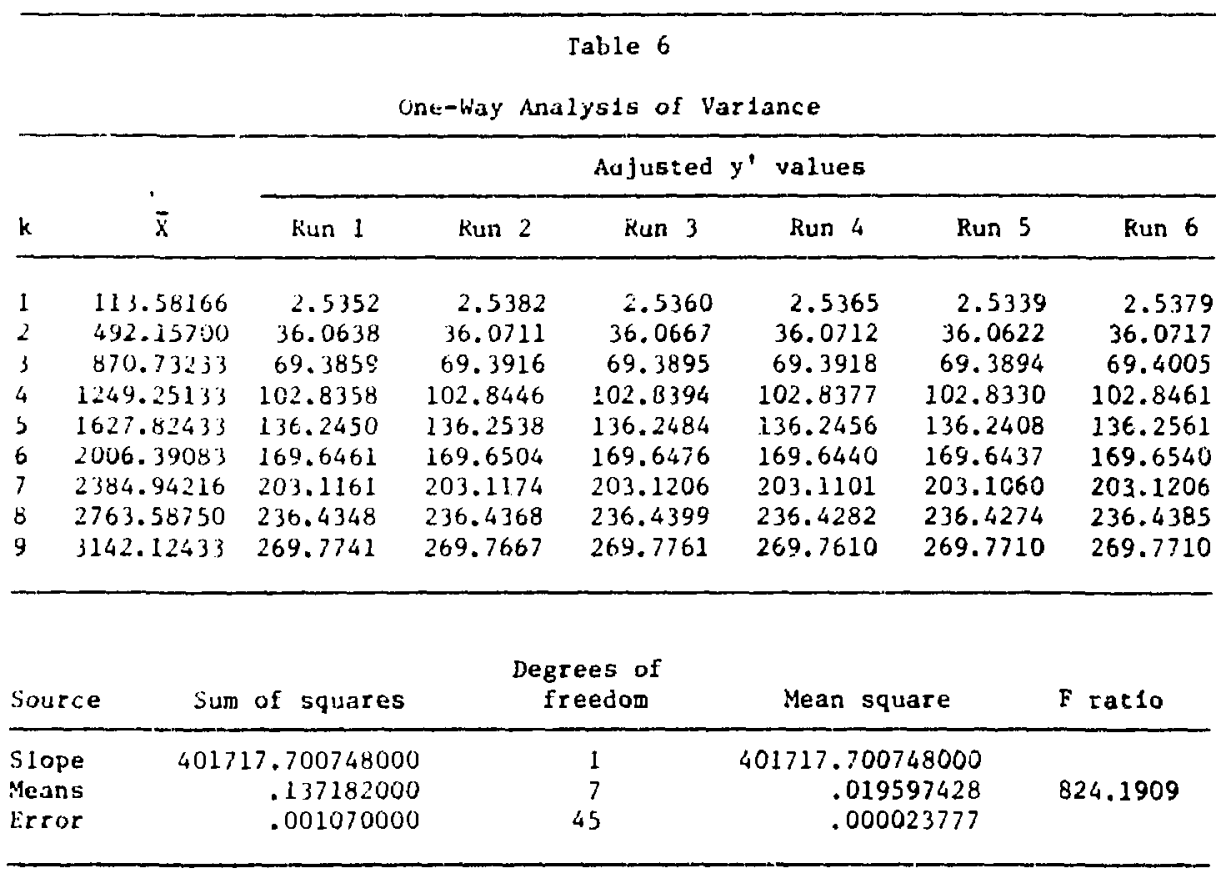

The adjusted $y^{\prime}{ }_{j i}$ values were then fitted to the $\bar{x}_{i}$ values by the method described by Brownlee $4 b$ for linear regression with several observations on $y$ at $x_{1}$. The residuals are plotted in Figure 3. The means squares are summartzed in Table 7. The F ratio of the mean squares of the group means about their line to the mean square of the replicate $y^{\prime}{ }_{j i}$ measurements is significant at the $\alpha=$ 0.001 level; that is, there is a signiflcant lack of fit of the group means to a straight line. The estimates of the coefficients of the linear least-squares fit based on the nine $\bar{x}, \bar{y}^{\prime}$ points are given in the last line of Table 4 . The preceding linc glves the estimates of the coefficlents of the linear leastsquares $f$ it based on the unadjusted $54 x, y$ pairs. 


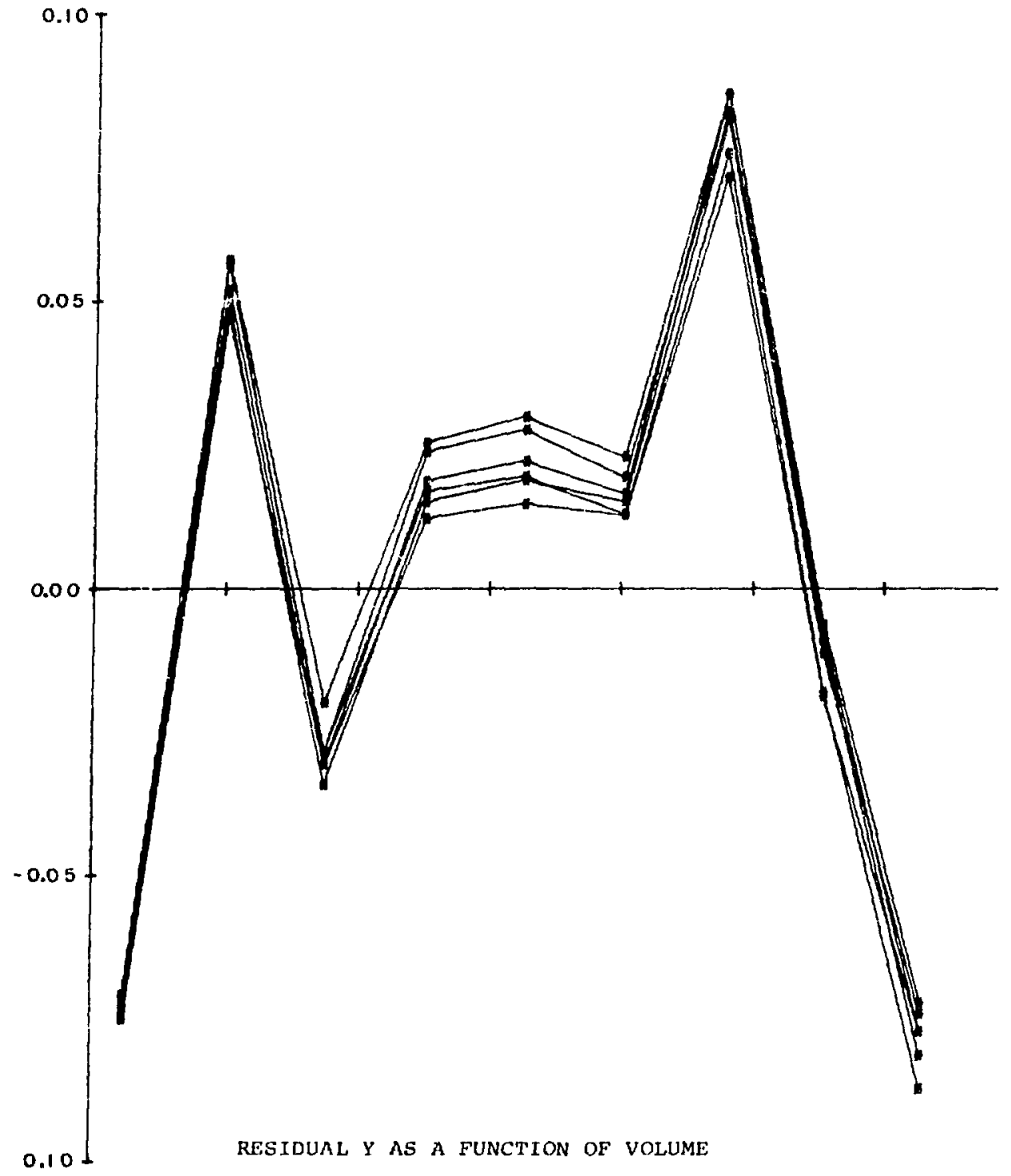

Figure 3. Plot of residuals about the $\bar{x}, \bar{y}$ lease-squares line. 
Table 7

Comparison of Methods of Analysis and Standard Deviation of the Slope

\begin{tabular}{ccc} 
Method used & $\begin{array}{c}\text { Fstimate of \% standard } \\
\text { deviation of slope }\end{array}$ & $\begin{array}{c}\text { Degrees of } \\
\text { freedom }\end{array}$ \\
\hline Observed 6 calibrations & 0.001026 & 5 \\
Sum of all 54 points & 0.008134 & 52 \\
Nine $\bar{x}, \bar{y}$ points & 0.022085 & 7 \\
\hline
\end{tabular}

Attempts to improve this linear fit by use of a quadratic or cubic polynominal fit were unsuccessful. Since the measurements involve fust one pressure instrument and one tank, there is no basis, without additional information, for assigning the lack of fit either to nonlinearity of the instrument response or to imperfections in the tank. Subsequent data have shown that the major source of error is irregularity i.2 the cross sectional area of the tank.

Since the investigation of higher-degree polynominals did not produce positive results, it is concluded that the "best" equation is the linear equation based on the nine $\bar{x}, \bar{y}$ ' points. Before proceeding further the analyst should maxe sure that the standard deviation of the slope is not underestimated. A comparison of this value with the spread of the plotted residuals is useful. In comparing Figure 3 with Figure 2 it is seen that the adjustment of the $y_{j i}$ values to $\bar{x}_{i}$ has increased the vertical spread of the residuals: this is a typical outcome.

A comparison of the estimates of the standard deviation of the slope due to the method of combining the $54 x_{j 1}, y_{j i}$ observations is given in Table 7 . 


\section{EXAMPLE 3 - PROCESS TANK DATA I}

This example, from data supplied by Wilson, ${ }^{7}$ 1llustrates the case in which (as In the preceding example) the replications of the calibration runs essentially comprise repeated measurements of a single run, and the major source of error is due to changes in the cross sectional area of the tank. In this example, however, $e_{t}$ can be eliminated by use of a polynominal fit. With the effect of the diameter changes in the tank removed, a signilicant difference between the runs was apparest.

The data are for three repeated callbration runs of 10 increments of 20 liters each with the first increment of each rur offset by 0.511 ter. In chis analysis the data are coded by dividing each $x$ datum by 100 . This linear transformation has no effect on lincarity of regression or on the analysis of variance and does not alter the estimate of the $y$ intercept or the shape of the plot of the $y$ residuals.

The results of fitting the calibration data by the independent linear model are shown in Tables 8 and 9 , and the residuals from the combined runs are plotted in Figure 4. The value of $u$ was $<-2$ in all three runs. The plot shows that the residuals are not randomly distributed but fall on a smooth curve resembling a parabcla. In Table 10 the $F$ ratio of the mean square due to the difference of the individual slopes compared with the mean square of the points about the individual lines is significantly low at the $\alpha=0.01$ level. All these results indicate the presence of $e_{t}$ as the major source of error. The pattern of the residuals in Figure 4 suggests that a polynomial fit may be appropriate.

One good feature of the calibration is that all increments, for all three runs, are of equal size, and therefore the data permtt the use of orthogonal polynominal techniques. ${ }^{3 b}$ Linear, quadratic, and cubic lines were fitted to 
Table 8

Linear Least-Squares Awalysis - Example 3

\begin{tabular}{|c|c|c|c|c|c|c|c|c|}
\hline $\begin{array}{l}\text { Pt. } \\
\text { No. }\end{array}$ & $\begin{array}{l}\text { Ols } \\
\mathrm{x}\end{array}$ & $\begin{array}{c}\text { Obs } \\
y\end{array}$ & $\begin{array}{c}\text { Pred. } \\
y\end{array}$ & $\begin{array}{c}\text { Resid. } \\
y\end{array}$ & $\begin{array}{l}\text { Cusum } \\
\text { resid. }\end{array}$ & $R_{n}$ & $\begin{array}{c}\text { Pred. } \\
x\end{array}$ & $\begin{array}{c}\text { Resid. } \\
x\end{array}$ \\
\hline \multicolumn{9}{|c|}{ Run 1} \\
\hline 1 & .280 & 1.300 & 1.602 & .302 & .302 & 2.195 & .144 & -.135 \\
\hline 2 & .480 & 2.000 & 2.049 & .049 & .352 & .332 & .457 & -.022 \\
\hline 3 & .680 & 2.580 & 2.495 & -.084 & .267 & .546 & .717 & .037 \\
\hline 4 & .880 & 3.100 & 2.941 & -.158 & .109 & .993 & .950 & .070 \\
\hline 5 & 1.080 & 3.550 & 3.387 & -.162 & -.053 & 1.003 & 1.152 & .072 \\
\hline 6 & 1.280 & 3.980 & 3.834 & $-.1<5$ & -.198 & .903 & 1.345 & .065 \\
\hline 7 & 1.480 & 4.350 & 4.280 & -.069 & -.268 & .437 & 1.511 & .031 \\
\hline 8 & 1.680 & 4.750 & 4.726 & -.023 & -.291 & .151 & 1.690 & .010 \\
\hline 9 & 1.880 & 5.100 & 5.172 & .072 & -.219 & .492 & 1.847 & -.032 \\
\hline 10 & 2.080 & 5.400 & 5.619 & .219 & .000 & 1.587 & 1.981 & -.098 \\
\hline \multicolumn{9}{|c|}{ kun 2} \\
\hline 1 & .285 & 1.400 & 1.685 & .285 & .285 & 2.215 & .157 &.- .127 \\
\hline 2 & .485 & 2.120 & 2.131 & .011 & .296 & .081 & .479 & -.005 \\
\hline 3 & .685 & 2.600 & 2.577 & -.022 & .273 & .158 & .695 & .010 \\
\hline 4 & .885 & 3.190 & 3.023 & -.166 & .106 & 1.122 & .959 & .074 \\
\hline 5 & 1.085 & 3.630 & 3.469 & -.160 & -.054 & 1.067 & 1.157 & .072 \\
\hline 6 & 1.285 & 4.040 & 3.914 & -.125 & -.179 & .829 & 1.341 & .056 \\
\hline 7 & 1.485 & 4.440 & 4.360 & -.079 & -.258 & .531 & 1.520 & .035 \\
\hline 8 & 1.685 & 4.820 & 4.806 & -.013 & -.271 & .091 & 1.690 & .005 \\
\hline 9 & 1.885 & 5.180 & 5.252 & .072 & -.198 & .527 & 1.852 & -.032 \\
\hline 10 & 2.085 & 5.500 & 5.698 & .198 & .000 & 1.543 & $1 . \overline{9} 95$ & -.089 \\
\hline \multicolumn{9}{|c|}{ Run 3} \\
\hline 1 & .290 & 1.400 & 1.697 & .297 & .297 & 2.221 & .155 & -.134 \\
\hline 2 & .490 & 2.090 & 2.141 & .051 & .348 & .357 & .466 & -.023 \\
\hline 3 & .690 & 2.680 & 2.584 & -.095 & .253 & .632 & .732 & .042 \\
\hline 4 & .890 & 3.180 & 3.028 & -.151 & .102 & .979 & .958 & .068 \\
\hline 5 & 1.090 & 3.640 & 3.472 & -.167 & -.065 & 1.070 & 1.165 & .075 \\
\hline 6 & 1.290 & 4.040 & 3.915 & -.124 & -.189 & .791 & 1.345 & .055 \\
\hline 7 & 1.490 & 4.440 & 4.359 & -.080 & -.270 & .520 & 1.526 & .036 \\
\hline 8 & 1.690 & 4.810 & 4.803 & -.006 & -.277 & .045 & 1.693 & .003 \\
\hline 9 & 1.890 & 5.170 & 5.246 & .076 & -.200 & .534 & $1.85 j$ & -.034 \\
\hline 10 & 2.090 & 5.490 & 5.690 & .200 & .000 & 1.495 & 1.999 & -.090 \\
\hline
\end{tabular}




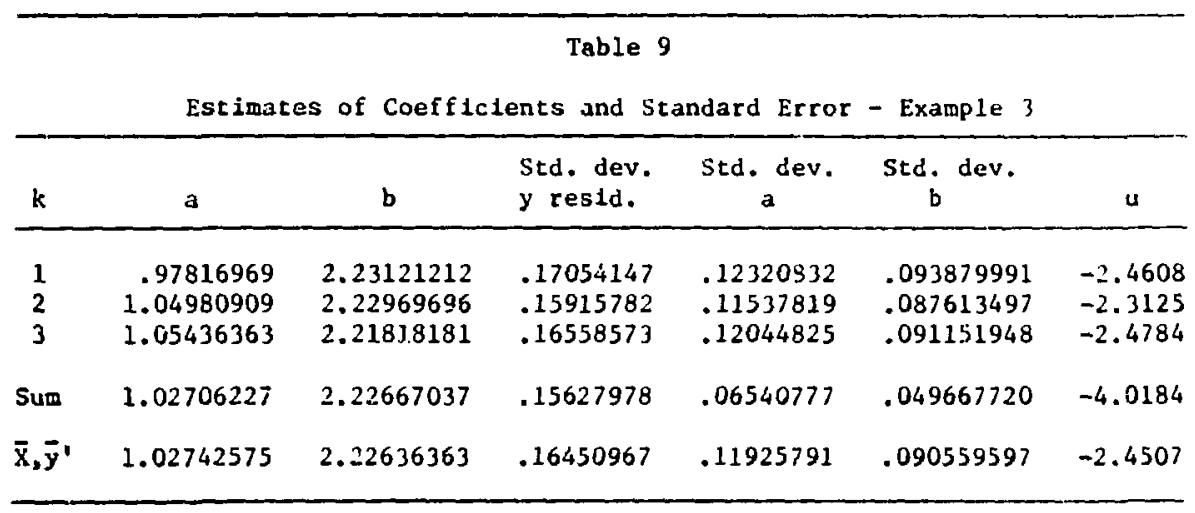

Table 10

Analysis of Covariance

\begin{tabular}{|c|c|c|c|c|}
\hline Source of varlance & $\begin{array}{l}\text { Sum of } \\
\text { squares }\end{array}$ & $\begin{array}{l}\text { Degrees } \\
\text { of } \\
\text { freedorn }\end{array}$ & $\begin{array}{l}\text { Mean } \\
\text { square }\end{array}$ & $\begin{array}{c}F \\
\operatorname{rat} 10\end{array}$ \\
\hline $\begin{array}{l}\text { Between } \hat{b} \text { and } \bar{b} \\
\text { Deviations of group } \\
\text { means about their } \\
\text { least-squares line } \\
\text { Between individual slopes } \\
\text { Deviations of individual } \\
\text { points about thelr } \\
\text { least-squares lines } \\
\text { About overall line } \\
\text { Dus to overall line }\end{array}$ & $\begin{array}{r}.654673939 \\
.683854355 \\
49.087282311\end{array}$ & $\begin{array}{r}24 \\
28 \\
1\end{array}$ & $\begin{array}{r}.027278080 \\
.024423369 \\
49.087282311\end{array}$ & $\begin{array}{l}.38131 \\
.00614\end{array}$ \\
\hline
\end{tabular}




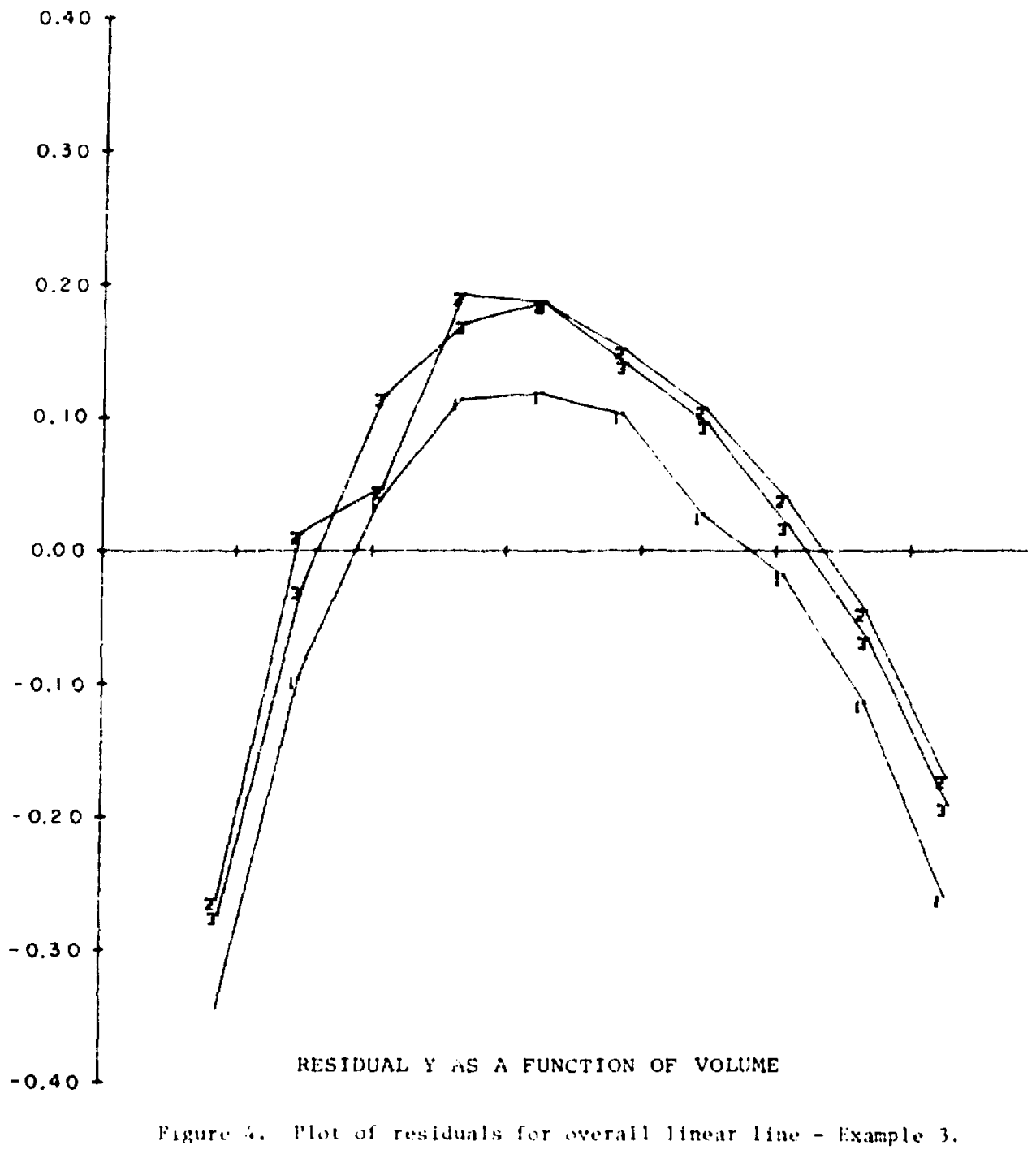


the data by the method of orthogonal polynominals. Thesc resules are presented in Table 11.

Inspection of the residual y values shows the improvement of the culic fit wer the quadratis and linear fits. Other results are given in Table 12. The interpretation of the significant $F$ tests is that, given the null hypothesis of no factor eife:c, the linear, quadratic and cubic coefficients are significant except for the cubic coefficient for run 2. The critical value for $F[u=0.005(1,6)]$ is 18.635 , and $y$ residuals for the cubic fit in run 2 of lable 12 are only narginally better than that for the quadratic fit. The interpretation of the $F$ test in run ? is that the improvement of the cubic over the quadratic fit is not significant. In the overall line the critical f value for $F[2=0.005(1,26)]$ is 9.41 and the cubic coefficient is highly significant.

The data from the three calibration runs were pooled and the cubic equaltion was ficted to the datia. The plot of the residuals on the overall cubie fit are shown in Figure 5 . The difference between the first run and the other two runs may be due to the tank being dry for run 1 and wet for runs 2 and 3 , or it may he due to a zero of set on the manometer in run 1 . The shapes of the three curves are in general agreement and provide a profile of the cross sectional area of the tank. The peak and valley formed by the second and third points of run 2 are self-canceling and are probably due to a data handing error or to misreading of the manometer. Unlike ersors associated with the measurement of the increments, a misreading of the manometer is a recoverable error.

The residual data for the cubic fit was next examined by using the twoway crossed classiflcation model for the analysis of variance. The results are presented in Table 13. The hypotheses that there are no run and point effects were both rejected. The run effect was not detected in the analysis of covari- 


\begin{tabular}{|c|c|c|c|c|c|c|c|c|}
\hline & & & & Table & & & & \\
\hline & & & Polynor & dal Least-5 & vares An & $1 y$ sis & & \\
\hline & & & & Predicted & & & Residual y & \\
\hline No. & $x$ & $y$ & Cubic & Quadratic & Linear & Cubic & Quadratic & Linear \\
\hline Run & & & & & & & & \\
\hline 1 & .280 & 1.300 & $1.31:$ & 1.357 & 1.602 & .013 & .057 & .302 \\
\hline 2 & .480 & 2.000 & 1.981 & 1.967 & 2.049 & -.018 & -.032 & .049 \\
\hline 3 & .680 & 2.580 & 2.572 & 2.536 & 2.995 & -.007 & -.043 & -.084 \\
\hline 4 & .880 & 3.100 & 3.096 & 3.064 & 2.941 & -.003 & -.035 & -.158 \\
\hline 5 & 1.080 & 3.550 & 3.564 & 3.551 & 3.387 & .014 & .001 & -.162 \\
\hline 6 & 1.280 & 3.980 & 3.985 & 3.997 & 3.834 & .005 & .017 & -.145 \\
\hline 7 & 1.480 & 4.350 & 4.370 & 4.403 & 4.280 & .020 & .053 & -.069 \\
\hline 8 & 1.680 & 4.750 & 4.731 & 4.767 & 4.726 & -.018 & .017 & -.023 \\
\hline 9 & 1.880 & 5.100 & 5.076 & 5.091 & 5.172 & -.023 & -.008 & .072 \\
\hline 10 & 2.080 & 5.400 & 5.417 & 5.373 & 5.619 & .017 & -.026 & .219 \\
\hline Run & & & & & & & & \\
\hline 1 & .285 & 1.400 & 1.419 & 1.458 & 1.685 & .019 & .058 & .285 \\
\hline 2 & .485 & 2.120 & 2.068 & 2.055 & 2.131 & -.051 & -.064 & .011 \\
\hline 3 & .685 & 2.600 & 2.647 & 2.614 & 2.577 & .047 & .014 & -.022 \\
\hline 4 & .885 & 3.190 & 3.165 & 3.136 & 3.023 & -.024 & -.053 & -.166 \\
\hline 5 & 1.085 & 3.630 & 3.631 & 3.620 & 3.469 & .001 & -.009 & -.160 \\
\hline 6 & 1.285 & 4.040 & 4.055 & 4.066 & 3.914 & .015 & .026 & -.125 \\
\hline 7 & 1.485 & 4.440 & 4.445 & 4.474 & 4.360 & .005 & .034 & -.079 \\
\hline 8 & 1.685 & 4.820 & 4.812 & 4.844 & 4.806 & -.007 & .024 & -.013 \\
\hline 9 & 1.885 & 5.180 & 5.164 & 5.177 & 5.252 & -.015 & -.002 & .072 \\
\hline 10 & 2.085 & 5.500 & 5.511 & 5.471 & 5.698 & .011 & -.028 & .198 \\
\hline Run & & & & & & & & \\
\hline 1 & .290 & 1.400 & 1.410 & 1.460 & 1.697 & .010 & .060 & .297 \\
\hline 2 & .490 & 2.090 & 2.079 & 2.062 & 2.141 & -.010 & -.027 & .051 \\
\hline 3 & .690 & 2.680 & 2.666 & 2.624 & 2.584 & -.013 & -.053 & -.095 \\
\hline 4 & .890 & 3.180 & 3.183 & 3.146 & 3.028 & .003 & -.033 & -.151 \\
\hline 5 & 1.090 & 3.640 & 3.644 & 3.630 & 3.472 & .004 & -.009 & -.167 \\
\hline 6 & 1.290 & 4.040 & 4.059 & 4.073 & 3.915 & .019 & .033 & -.124 \\
\hline 7 & 1.490 & 4.440 & 4.440 & 4.477 & 4.359 & .000 & .037 & -.080 \\
\hline 8 & 1.690 & 4.810 & 4.800 & 4.342 & 4.803 & -.009 & .032 & -.006 \\
\hline 9 & 1.890 & 5.170 & 5.151 & 5.167 & 5.246 & -.018 & -.002 & .076 \\
\hline 10 & 2.090 & 5.490 & 5.503 & 5.453 & 5.690 & .013 & $-.030^{\circ}$ & .200 \\
\hline
\end{tabular}


Table 12

Selected Results oi Polynomial Analysis

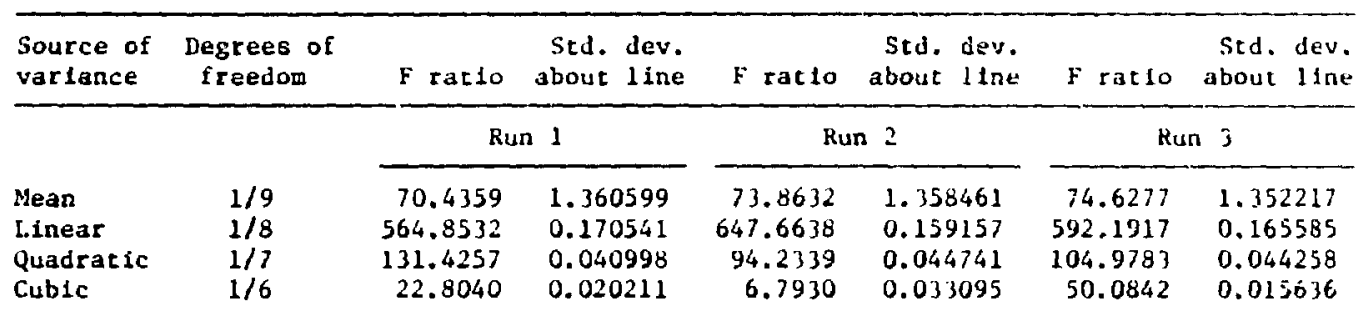

\section{Overall Line}

$\begin{array}{lrrr}\text { Mean } & 1 / 29 & 234.8808 & 1.310055 \\ \text { Linear } & 1 / 28 & 2009.8488 & 0.156279 \\ \text { Quadrat1c } & 1 / 27 & 240.4441 & 0.050566 \\ \text { Cublc } & 1 / 26 & 19.1939 & 0.039084\end{array}$

Estimate of Coefficlents for the overall Line

\begin{tabular}{lllll}
\hline & $a$ & $b_{1}$ & $b_{2}$ & $b_{3}$ \\
\hline Cub1c & 0.2826 & 4.2999 & -1.2826 & 0.2223 \\
Quadratic & 0.4981 & 3.3938 & -0.4925 & \\
Linear & 1.0271 & 2.2267 & & \\
\hline
\end{tabular}




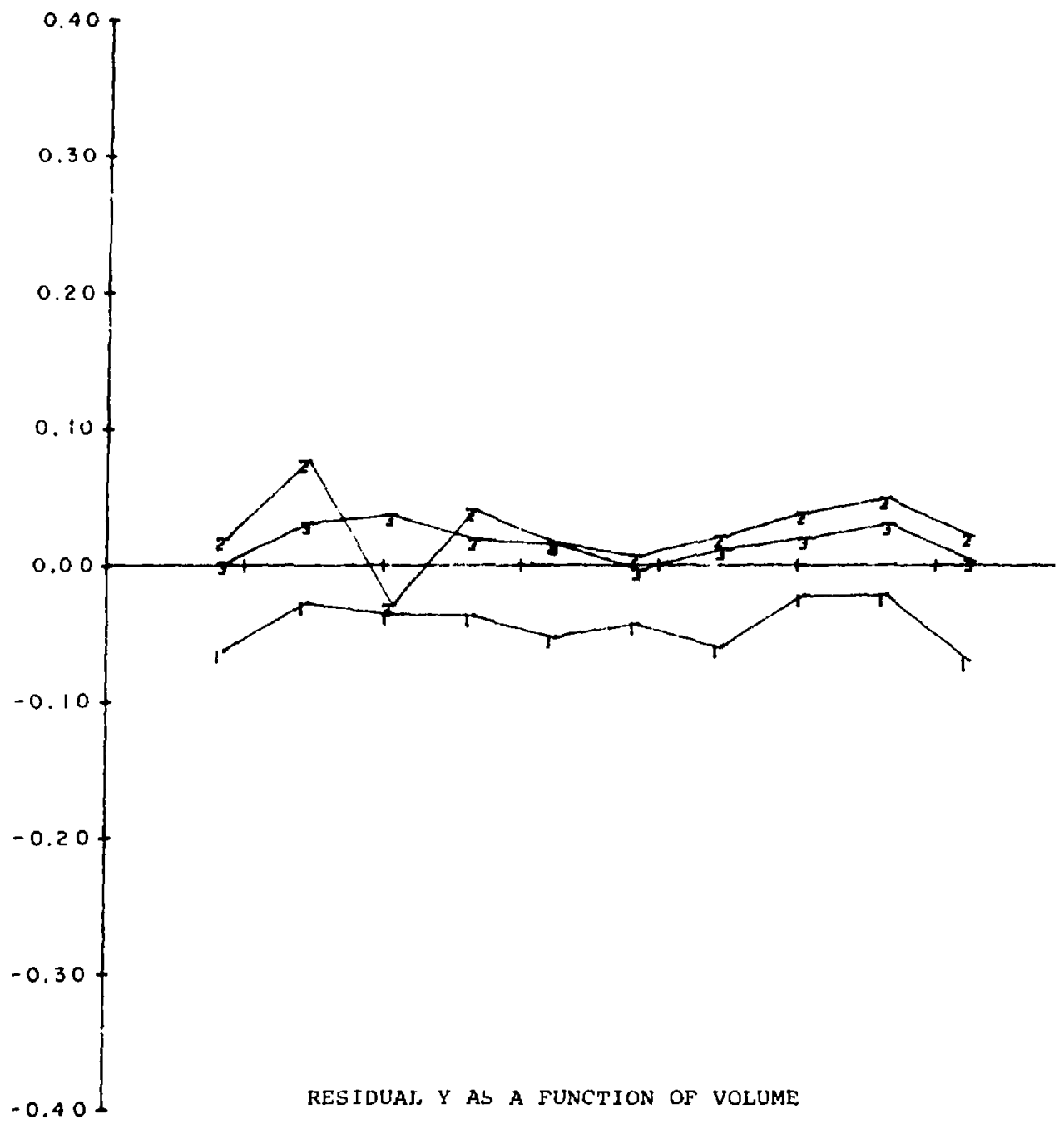

Flgure 5. Plot of residuals for overall cubic line - tixample 3. 


\section{Table 13}

Two-Crossed Classification ANova of Cubie Reslduals

\begin{tabular}{|c|c|c|c|c|}
\hline Pt. No. & Run 1 & Run 2 & Kun 3 & Average \\
\hline 1 & .0636 & -.0187 & -.0011 & .0146 \\
\hline 2 & .0276 & -.0767 & -.0312 & -.0267 \\
\hline 3 & .0350 & .0288 & -.0373 & .0088 \\
\hline 4 & .0364 & -.0413 & -.0190 & -.0079 \\
\hline 5 & .0522 & -.0167 & -.0157 & .0066 \\
\hline 6 & .0431 & -.0067 & .0032 & .0132 \\
\hline 7 & .0597 & -.0209 & -.0116 & .0090 \\
\hline 8 & .0224 & -.0387 & -.0198 & -.0120 \\
\hline 9 & .0218 & -.0494 & -.0307 & $-.019:$ \\
\hline 10 & .0686 & -.0226 & -.0038 & .0140 \\
\hline Average & .0430 & -.0262 & -.0167 & .00000 \\
\hline Source & Sum of squares & $\begin{array}{l}\text { Degrees of } \\
\text { freedom }\end{array}$ & Yean square & Fratio \\
\hline Between points & .006274315 & 6 & .001045719 & 3.6683 \\
\hline Bezween runs & .028224948 & 2 & .014112474 & 49.5056 \\
\hline P $x$ R interaction & .005131218 & 18 & .000285067 & \\
\hline
\end{tabular}


ance of the linear leatsi-squares fit (lable 10). The reason for this is that In the analysis of cuvariance the mein square of the deviations of the individual points about their least-squares lines includes the lack of fit to the linear line which may result in an overestimation of the mean square. Consequently all F ratius bised on this mean square will be too low (see Section VI). The interaction mean square of lable 13 is the best estimate of the deviation of the individual points about their cubic line and thus of the measurement variince, $s_{y}^{2}$.

An exumination of the plot of the residuals from the overall cubie fit (Fig. 5) clearly shows that the difference between runs is due to a change in intercept and not due to variations in slope. The best est Imate of the variance of the overall mear ( $\bar{x}, \bar{y}$ point) is obtained by dividing the between run mean square of Table 13 by 30 , the number of $x, y$ pairs.

Because the hypothesis of no point effect was rejected, the technique in the previous example wis used to adjust values of the dependent variable to take account of the small differences among the associated values of the independent variable. Jor polynomial relationships, correction of the neighboring pairs to the same $\bar{x}_{i}$ is made by using the relationship $y_{i j}^{\prime}=y_{i j}-b^{\prime}\left(x_{i j}-\bar{x}_{i}\right)$ where $b^{\prime}$ is the derivative of the cublc fit evaluated at $\bar{x}_{i}$ (see section VII). In this particular example, since $x_{i j}-\bar{x}_{i}$ is -0.005 for all $i$ in run 1 , zero in run 2 , and +0.005 for all $\mathrm{i}$ in run 3 , the use of a simple average at each point would not introduce any error.

The results of the polynomial fits to the adjusted ten $\bar{x}, \bar{y}$ ' points are presented in Table 14. Wille in this example the values for the coefficients are nearly the same as for the overall cubic line (Table 12), the adjusted data cubic line provides the valid estimates of the mean squares for the analysis of 
Table 14

Analysis of Polynomial fits to Adjusted Data

\begin{tabular}{|c|c|c|c|c|c|c|c|c|}
\hline \multirow{2}{*}{$\begin{array}{l}\text { Pt. } \\
\text { No. }\end{array}$} & \multirow[b]{2}{*}{$\mathrm{x}$} & \multirow[b]{2}{*}{$y$} & \multicolumn{3}{|c|}{ Predicted $y$} & \multicolumn{3}{|c|}{ Residual y } \\
\hline & & & Cubic & Quadratic & Linear & Cubic & Quadracic & linear \\
\hline 1 & .285 & 1.366 & 1.381 & 1.425 & 1.661 & .014 & .058 & .295 \\
\hline 2 & .485 & 2.070 & 2.043 & 2.028 & 2.107 & -.026 & -.041 & .037 \\
\hline 3 & .685 & 2.620 & 2.628 & 2.591 & 2.552 & .008 & -.028 & -.067 \\
\hline 4 & .885 & 3.156 & 3.148 & 3.115 & 2.997 & -.007 & -.040 & -.158 \\
\hline 5 & 1.085 & 3.606 & 3.613 & 3.600 & 3.443 & .006 & -.006 & -.163 \\
\hline 6 & 1.285 & 4.020 & 4.033 & 4.045 & 3.888 & .013 & .025 & -.131 \\
\hline 7 & 1.485 & 4.410 & 4.419 & 4.451 & 4.333 & .009 & .041 & -.076 \\
\hline 8 & 1.685 & 4.793 & 4.781 & 4.818 & 4.778 & -.012 & .024 & -.014 \\
\hline 9 & 1.885 & 5.150 & 5.130 & 5.145 & 5.224 & -.019 & -.004 & .074 \\
\hline 10 & 2.085 & 5.463 & 5.477 & 5.433 & 5.669 & .014 & -.030 & .206 \\
\hline
\end{tabular}

Estimates of Coefficients of Adjusted Data

\begin{tabular}{llccc}
\hline & $\mathrm{a}$ & $\mathrm{b}_{1}$ & $\mathrm{~b}_{2}$ & $\mathrm{~b}_{3}$ \\
\hline Cubic & .2852 & 4.1912 & -1.2745 & .2200 \\
Quadratic & .4985 & 3.3934 & -.4924 & \\
Linear & 1.0274 & 2.2264 & \\
\hline
\end{tabular}

variance presented in Table 15. The cubic coefficient is highly significant so the best calibration 1 ine is the cubic fit to the adjusted ten $\bar{x}, \bar{y}$, points. Since Table 15 is based on a set of data where each point consists of the average of three $x, y^{\prime}$ pairs, it is not unexpected that the variance of the points about the line is roughly one-third of the between-points mean square in Table 13. 


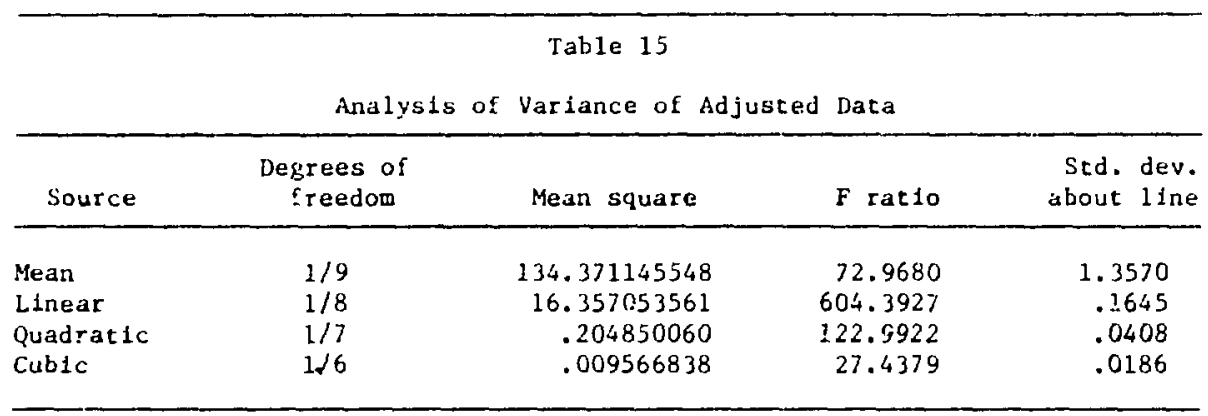

In this example, additional runs would improve the reliability of the calibration equation whereas more points per run would not. This is the opposite of the case for the preceding example, in which more runs did not improve the reliablitiy of the equation but more points per run would better define the tank.

V. EXAMPLE 4 - PROCESS TANK DATA II

Data on the calibration of a process tank, supplied by Anderson, 8 were fitted by using the independent model, and the results were examined by analysis of covariance. The least-squares equations for the four runs are

$$
\begin{aligned}
& Y_{1}=-1.408+9.561 \mathrm{x}_{1}, \\
& Y_{2}=-1.462+9.571 \mathrm{X}_{2}, \\
& Y_{3}=-1.483+9.567 \mathrm{X}_{3}, \\
& Y_{4}=-1.454+9.509 \mathrm{X}_{4} .
\end{aligned}
$$

Inspection of Eq. (7) suggests that runs 1 and 4 are different: the estimate is low in run 1 for the $y$ intercept and in run 4 for the slope. Data for the four runs and the usual least-squares listings are given in Table 16. The 


\begin{tabular}{|c|c|c|c|c|c|c|c|c|}
\hline & & & & able 16 & & & & \\
\hline & & Linear & Least-Sq & res Anal & sis $-E x$ & mple 4 & & \\
\hline $\begin{array}{l}\text { Pt. } \\
\text { No. }\end{array}$ & $\begin{array}{c}\text { Obs } \\
\mathrm{x}\end{array}$ & $\begin{array}{c}\text { Obs } \\
y\end{array}$ & $\begin{array}{c}\text { Pred. } \\
y\end{array}$ & $\begin{array}{c}\text { Resid } \\
y\end{array}$ & $\begin{array}{l}\text { Cusum } \\
\text { resid. }\end{array}$ & $\mathbf{R}_{n}$ & $\begin{array}{c}\text { Pred } \\
x\end{array}$ & $\begin{array}{c}\text { Res 1d } \\
\mathbf{x}\end{array}$ \\
\hline Run & & & & & & & & \\
\hline 1 & .6818 & 5.160 & 5.110 & -.049 & -.049 & 1.237 & .6869 & .0051 \\
\hline 2 & .9103 & 7.230 & 7.295 & .065 & .015 & 1.555 & .9034 & -.0068 \\
\hline 3 & 1.1350 & 9.440 & 9.443 & .003 & .019 & .081 & 1.1346 & -.0003 \\
\hline 4 & 1.3636 & 11.650 & 11.629 & -.020 & -001 & .468 & 1.3657 & .0021 \\
\hline 5 & 1.5907 & 13.810 & 13.800 & -.009 & -.011 & .212 & 1.5917 & .0010 \\
\hline 6 & 1.8182 & 16.020 & 15.975 & -.044 & -.055 & .976 & 1.8228 & .0046 \\
\hline 7 & 2.0458 & 18.140 & 18.151 & .011 & -.044 & .254 & 2.0445 & -.0012 \\
\hline 8 & 2.2734 & 20.270 & 20.327 & .057 & .013 & 1.275 & 2.2673 & -.0060 \\
\hline 9 & 2.5000 & 22.420 & 22.494 & .074 & .087 & 1.666 & 2.4922 & -.0077 \\
\hline 10 & 2.7267 & 24.720 & 24.661 & -.058 & .029 & 1.346 & 2.7328 & .0061 \\
\hline 11 & 2.9574 & 26.900 & 26.867 & -.032 & -.003 & .781 & 2.9608 & .0034 \\
\hline 12 & 3.1377 & 28.970 & 28.973 & .003 & .000 & .087 & 3.1773 & -.0003 \\
\hline Run & & & & & & & & \\
\hline 1 & .5678 & 3.980 & 3.972 & -.007 & -.007 & .206 & .5686 & .0008 \\
\hline 2 & .7940 & 6.190 & 6.137 & -.052 & -.060 & 1.334 & .7995 & .0055 \\
\hline 3 & 1.2482 & 10.470 & 10.484 & .014 & -.046 & .337 & 1.2467 & -.0014 \\
\hline 4 & 1.4753 & 12.680 & 12.657 & -.022 & -.068 & .513 & 1.2467 & -.0014 \\
\hline 5 & 1.7024 & 14.750 & 14.831 & .081 & .012 & 1.863 & 1.6938 & -.0085 \\
\hline 6 & 1.9295 & 16.960 & 17.004 & .044 & .057 & 1.023 & 1.9248 & -.0046 \\
\hline 7 & 2.1576 & 19.170 & 19.188 & .018 & .076 & .412 & 2.1557 & -.0018 \\
\hline 8 & 2.3847 & 21.390 & 21.361 & -.028 & .047 & .650 & 2.3876 & .0029 \\
\hline 9 & 2.6118 & 23.600 & 23.535 & -.064 & -.017 & 1.509 & 2.6185 & .0067 \\
\hline 10 & 2.8389 & 25.660 & 25.708 & .048 & .031 & 1.163 & 2.8338 & -.0050 \\
\hline 11 & 3.0660 & 27.880 & 27.882 & .002 & .034 & .057 & 3.0657 & -.0002 \\
\hline 12 & 3.2931 & 30.090 & 30.055 & -.034 & .000 & .874 & 3.2966 & .0035 \\
\hline Kun & & & & & & & & \\
\hline 1 & .6789 & 5.010 & $5.01 \mathrm{j}$ & .001 & .001 & .001 & .039 & -.0001 \\
\hline 2 & .9078 & 7.220 & 7.201 & -.018 & -.016 & .364 & .9097 & .0019 \\
\hline 3 & 1,1367 & 9.420 & 9. 391 & -.028 & -.045 & .548 & 1.1396 & .0029 \\
\hline 4 & 1.3656 & 11.490 & 11.581 & .091 & .046 & 1.707 & 1.3560 & -.0095 \\
\hline 5 & i. .5917 & 13.840 & 13.744 & -.095 & -.049 & 1.766 & 1.6017 & .0100 \\
\hline 6 & 1.8183 & 15.900 & 15.911 & .013 & -.037 & .218 & 1.8170 & -.0012 \\
\hline 7 & 2.0440 & 18.110 & 18.071 & -.038 & -.076 & .711 & 2.0480 & .0040 \\
\hline 8 & 2.2734 & 20.180 & 20.265 & .085 & .009 & 1.579 & 2.2644 & -.0089 \\
\hline 9 & 2.4995 & 22.380 & 22.428 & .048 & .057 & .911 & 2.4944 & -.0050 \\
\hline 10 & 2.7266 & 24.590 & 24.601 & .011 & .068 & .215 & 2.7254 & -.0011 \\
\hline 11 & 2.9537 & 26.800 & 26.773 & -.026 & .042 & .521 & 2.9564 & .0027 \\
\hline 12 & 3.1830 & 29.010 & 28.967 & -.042 & .000 & .889 & 3.1874 & .0044 \\
\hline
\end{tabular}




\begin{tabular}{|c|c|c|c|c|c|c|c|c|}
\hline & & & $\mathrm{Tab}$ & $16(\mathrm{cot}$ & 'd) & & & \\
\hline $\begin{array}{l}\text { Pt. } \\
\text { No. }\end{array}$ & $\begin{array}{c}\text { Obs } \\
\mathbf{x}\end{array}$ & $\begin{array}{c}\text { Obs } \\
y\end{array}$ & $\begin{array}{c}\text { Pred. } \\
y\end{array}$ & $\begin{array}{c}\text { ResId } \\
y\end{array}$ & $\begin{array}{l}\text { Cusum } \\
\text { resid. }\end{array}$ & $\mathbf{R}_{n}$ & $\begin{array}{c}\text { Pred. } \\
x\end{array}$ & $\begin{array}{c}\text { Resid } \\
x\end{array}$ \\
\hline \multicolumn{9}{|c|}{ Run 4} \\
\hline 1 & .6832 & 5.100 & 5.042 & -.057 & -.057 & 1.441 & .6892 & .0060 \\
\hline 2 & .9094 & 7.200 & 7.193 & -.006 & -.064 & .159 & .9101 & .0007 \\
\hline 3 & 1.1367 & 9.370 & 9.354 & -.015 & -.079 & .352 & 1.1383 & .0016 \\
\hline 4 & 1.3628 & 11.500 & 11.504 & .004 & -.074 & .165 & 1.3623 &. .0004 \\
\hline 5 & 1.5908 & 13.690 & 13.672 & -.017 & -.092 & .382 & 1.5926 & .0018 \\
\hline 6 & 1.8170 & 15.720 & 15.823 & .103 & .011 & 2.277 & 1.8060 & -.0109 \\
\hline 7 & 2.0450 & 17.970 & 17.991 & .021 & .033 & .477 & 2.0427 & -.0022 \\
\hline 8 & 2.2711 & 20.110 & 20.141 & .031 & .064 & .701 & 2.2677 & -.0033 \\
\hline 9 & 2.4982 & 22.270 & 22.301 & .031 & .096 & .701 & 2.4949 & -.0032 \\
\hline 10 & 2.7257 & 24.470 & 24.464 & -.005 & .090 & .127 & 2.7262 & .0005 \\
\hline 11 & 2.9504 & 26.620 & 26.601 & -.018 & .071 & .450 & 2.0523 & .0019 \\
\hline 12 & 3.1738 & 28.840 & 28.768 & -.071 & .000 & 1.795 & 3.1858 & .0075 \\
\hline
\end{tabular}


$y$ residuals are plotted in Figure 6. The estimates of the coefficients ind their standard errors are given in Table 17.

The results obtained in the analysis of covariance are summarized in Table 18, and they indica :e that the lines are parallel (hypothesis 1). However, hypothesis 2, that the four run means fall on a straight 1ine, was rejected at the $\alpha=0.001$ level. Hypothesis 3 is the assumption that there is no difference between $\hat{b}$ and $\bar{b} . *$ Hypothesis 3 was rejected at the $\alpha=0.05$ level.

Inspection of the plot of the residuals (Figure 6) suggests that run 4 might be the source of the rejections of hypotheses 2 and 3 . Data in the upper regions of the tank for calibration run 4 are substantially different from those for the other three calibration runs. Calculation of the overall line and the analysis of covariance were repeated with calibration run 4 omitted. These results are summarized in Tables 19 and 20 . Hypothesis 2 was again rejected, this time at the $\alpha=0.005$ level, which indicates that calibration run 4 was not the sole source of the lack of agreement between lines.

The analysis of covariance is relatively sensitive to changes in the data set means. A small shift in the $y$-intercept, or any other factor that results in a shift of the data set means, is indicated by a rejection of hypothesis 2 or 3 in the analysis of covariance.

With the refection of hypothesis 2 further analysis based on the combination of the three calibration runs by summing al.1 data points (Sum Iine in Table 19) is not valid. If possible, the physical cause of the differences in the group means should be determined and eliminated. The analyst at this point

*These terms are defined in Table 24. 


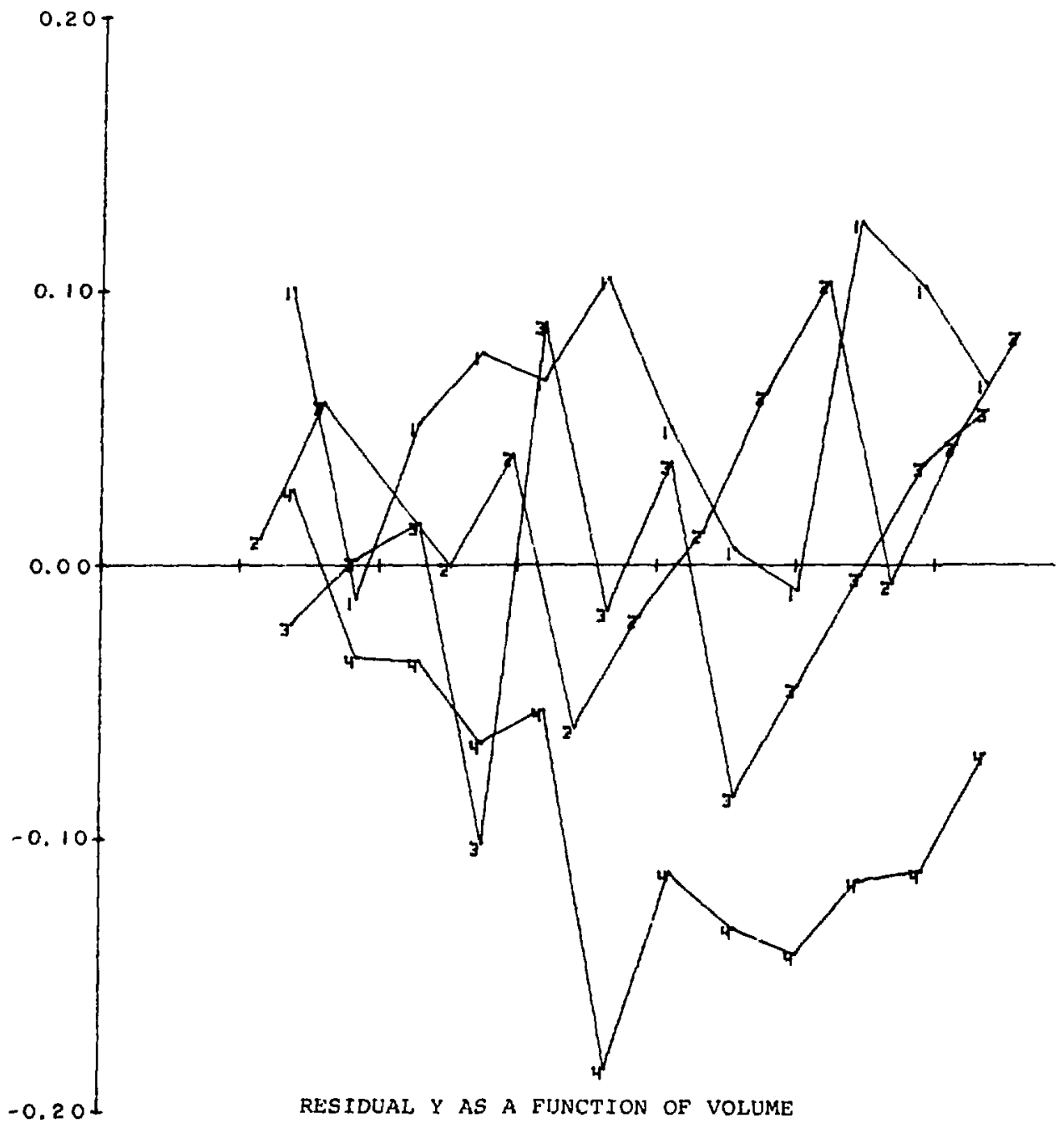

Figure 6. Plot of residuals for overall linear line - Example 4. 
Table 17

Estimates of Coefficients and Standard Errors - Example 4

\begin{tabular}{|c|c|c|c|c|c|c|}
\hline $\mathbf{K}$ & $\mathbf{a}$ & $\mathrm{b}$ & $\begin{array}{l}\text { Std. dev. } \\
\text { y resid. }\end{array}$ & sid. dev. & $\underset{b}{\text { std. dev. }}$ & $\mathbf{u}$ \\
\hline 1 & -1.40804573 & 9.56086334 & $.0476045:$ & .03653035 & .01752171 & -.1091 \\
\hline 2 & -1.4621540 & 9.57094091 & .04590323 & .03425007 & .01574595 & -.1420 \\
\hline 3 & -1.48282038 & 9.56650119 & .05713866 & .04331574 & .02101496 & 1.0453 \\
\hline 4 & -1.45412384 & 9.50896843 & .04759061 & .03654909 & .01754210 & -1.2384 \\
\hline Sum & -1.45447373 & 9.55338367 & .07504452 & .02855214 & .01357905 & -4.1138 \\
\hline $\bar{x}, \bar{y}+$ & -1.45237801 & 9.55255552 & .02312145 & .01762191 & .00836399 & -1.5563 \\
\hline
\end{tabular}

Yable 18

analysis of Covariance

\begin{tabular}{|c|c|c|c|c|}
\hline Source of variance & $\begin{array}{l}\text { Sum of } \\
\text { squares }\end{array}$ & $\begin{array}{l}\text { Degrees } \\
\quad \text { of } \\
\text { ireedom }\end{array}$ & $\begin{array}{c}\text { Mean } \\
\text { square }\end{array}$ & $\begin{array}{c}\text { F } \\
\text { ratio }\end{array}$ \\
\hline $\begin{array}{l}\text { Between } \hat{b} \text { and } \vec{b} \\
\text { Deviations of group } \\
\text { means dbout their }\end{array}$ & .013061025 & 1 & .013061025 & 5.27558 \\
\hline least-squares line & .128163535 & 2 & .064081767 & 25.88378 \\
\hline $\begin{array}{l}\text { Between individual slopes } \\
\text { Deviations of Individual } \\
\text { points about their }\end{array}$ & .018802750 & 3 & .006267583 & 2.53159 \\
\hline least-squares 11nes & .099029990 & 40 & .002475749 & \\
\hline About the overall line & .259057300 & 46 & .005631680 & \\
\hline Due to the overall line & $2800.32316: 7400$ & 1 & 2280.323109400 & \\
\hline
\end{tabular}


Table 19

Estimates of Coefficients and Standard Errors, Runs 1-?

\begin{tabular}{|c|c|c|c|c|c|c|}
\hline k & $\mathbf{a}$ & b & $\begin{array}{l}\text { Std. dev. } \\
\text { y resid. }\end{array}$ & $\underset{a}{\text { Std. dev. }}$ & $\underset{b}{\text { Std. dev. }}$ & u \\
\hline $\begin{array}{l}1 \\
2 \\
3\end{array}$ & $\begin{array}{l}-1.40804573 \\
-1.46215402 \\
-1.48282038\end{array}$ & $\begin{array}{l}9.56086334 \\
9.57094091 \\
9.56650119\end{array}$ & $\begin{array}{l}.04760452 \\
.04590323 \\
.05713366\end{array}$ & $\begin{array}{r}.03653035 \\
.03425007 \\
.04381574\end{array}$ & $\begin{array}{l}.01752171 \\
.01574595 \\
.02101496\end{array}$ & $\begin{array}{r}-.1091 \\
-.1420 \\
1.0453\end{array}$ \\
\hline Sum & -1.45122851 & 9.56627625 & .05458779 & .02391444 & .01130476 & -.8534 \\
\hline $\bar{x}, \bar{y}^{\prime}$ & -1.45187456 & 9.56687073 & .01847333 & .01407937 & .00668257 & -1.4011 \\
\hline
\end{tabular}

Table 20

Analysis of Covariance, Runs 1-3

\begin{tabular}{|c|c|c|c|c|}
\hline Source of variance & $\begin{array}{l}\text { Sum of } \\
\text { squares }\end{array}$ & $\begin{array}{l}\text { Degrees } \\
\text { of } \\
\text { freedom }\end{array}$ & $\begin{array}{l}\text { Mean } \\
\text { square }\end{array}$ & $\begin{array}{c}F \\
\text { ratio }\end{array}$ \\
\hline $\begin{array}{l}\text { Between } \hat{b} \text { and } \vec{b} \\
\text { Deviations of group } \\
\text { means about their }\end{array}$ & .000041608 & 1 & .000041608 & .01634 \\
\hline $\begin{array}{l}\text { least-squares line } \\
\text { Between the individual slopes } \\
\text { Deviations of individual } \\
\text { points about their }\end{array}$ & $\begin{array}{l}.024489767 \\
.000401440\end{array}$ & $\begin{array}{l}1 \\
2\end{array}$ & $\begin{array}{l}.024489767 \\
.000200720\end{array}$ & $\begin{array}{r}9.61875 \\
.07883\end{array}$ \\
\hline $\begin{array}{l}\text { least-squares Iines } \\
\text { About the overall line } \\
\text { Due to the overall line }\end{array}$ & $\begin{array}{r}.076381320 \\
.101314140 \\
2133.801741460\end{array}$ & $\begin{array}{r}30 \\
34 \\
1\end{array}$ & $\begin{array}{r}.002546044 \\
.002979827 \\
2133.801741460\end{array}$ & \\
\hline
\end{tabular}


lias two options; (a) to request more calibration runs, or (b) to accept the existing data and find the equation least likely to result in misrepresentation of the reliability of the measurements based on this calibration.

To obtain valid estimates of the coefficients and their standard errors, the analysis proceeded with adjustment of the data according to section VII. The results of the least-squares fit of the twelve $\bar{x}, \bar{y}^{\prime}$ points for all four data sets and for only the first three data sets are shown in Table 21 and 22 , respectively.

The results in Table 23 indicate that the linear analysis of runs 1 to 3 provides the more acceptable results. If the overall line had not been rejected because of hypothesis 2, it might have been preferred to the adjusted line on the basis of the lower $u$ value and a large estimate of the standard deviation of the slope.

A comparison of tile estimate of the standard deviation of the slope for the adjusted data for the three runs (line labeled $\bar{x}, \bar{y}^{\prime}$ in Table 19) with that of the estimate of the standard deviation of the slope obtained by summing all data points (line labeled Sum in Table 19) indicates that these estimates differ by approximately the factor square root of $k$, the number of calibration runs.

$$
\begin{aligned}
(0.011305) / \sqrt{3} & =0.006527 \\
& \sim 0.006716
\end{aligned}
$$

Examples 2 and 4 illustrate the hazard of uncritically combining data sets into an overall line and the importance of examining the curves fitted to the adjusted data. Additional discusstons of these examples are given in parts $A$ and $B$ of section VII. 
Table 21

One-way Analysis of Variance, Runs 1-4

\begin{tabular}{|c|c|c|c|c|c|}
\hline \multirow[b]{2}{*}{$\mathrm{k}$} & \multirow[b]{2}{*}{$\bar{x}$} & \multicolumn{4}{|c|}{ Adjusted $y^{\prime}$ values } \\
\hline & & Run 1 & Run 2 & Run 3 & Run 4 \\
\hline 1 & .6529 & 4.8841 & 4.7932 & 4.7618 & 4.8107 \\
\hline 2 & .8803 & 6.9441 & 7.0151 & 6.9579 & 6.9227 \\
\hline 3 & 1.1641 & 9.7184 & 9.6670 & 9.6822 & 9.6322 \\
\hline 4 & 1.3918 & 11.9196 & 11.8825 & 11.7405 & 11.7772 \\
\hline 5 & 1.6189 & 14.0794 & 13.9522 & 14.0998 & 13.9564 \\
\hline 6 & 1.8457 & 16.2831 & 16.1599 & 16.1622 & 15.9946 \\
\hline 7 & 2.0731 & 18.4008 & 18.3627 & 18.3880 & 18.2384 \\
\hline 8 & 2.3006 & 20.5303 & 20.5870 & 20.4403 & 20.3923 \\
\hline 9 & 2.5273 & 22.6815 & 22.7934 & 22.6463 & 22.5487 \\
\hline 10 & 2.7544 & 24.9853 & 24.8534 & 24.8563 & 24.7448 \\
\hline 11 & 2.9818 & 27.1338 & 27.0763 & 27.0691 & 26.9206 \\
\hline 12 & 3.2080 & 29.2597 & 29.2772 & 29.2490 & 29.1239 \\
\hline
\end{tabular}

\begin{tabular}{lrrrr} 
Souree & Sum of squares & $\begin{array}{c}\text { Degrees of } \\
\text { freedom }\end{array}$ & Nean square & F ratio \\
\hline Slope & 2789.332544120 & 1 & 2789.332544120 & 423078.2456 \\
Means & .021568580 & 10 & .002156858 & .3271 \\
Error & .237346100 & 36 & .006592947 & \\
\hline
\end{tabular}




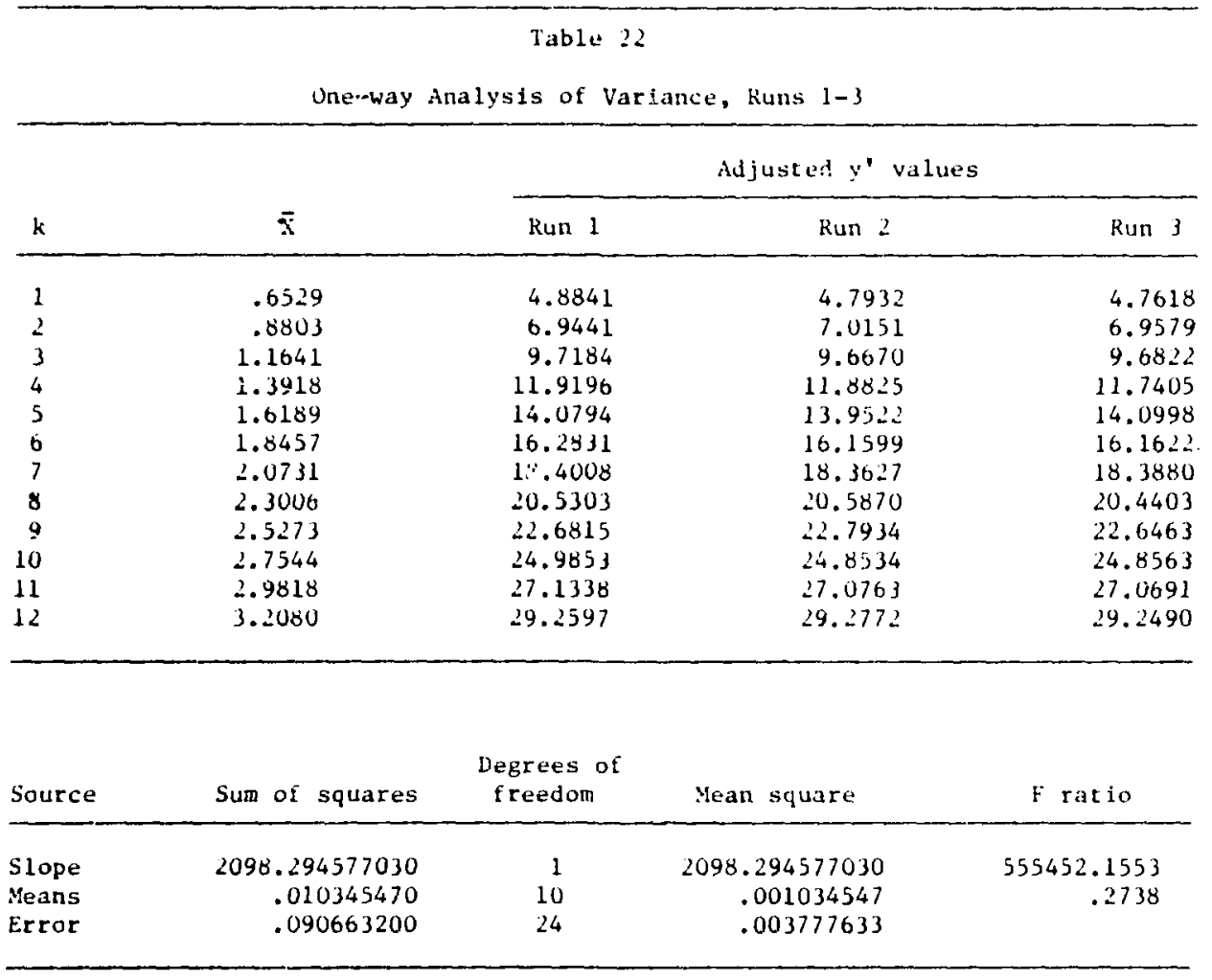




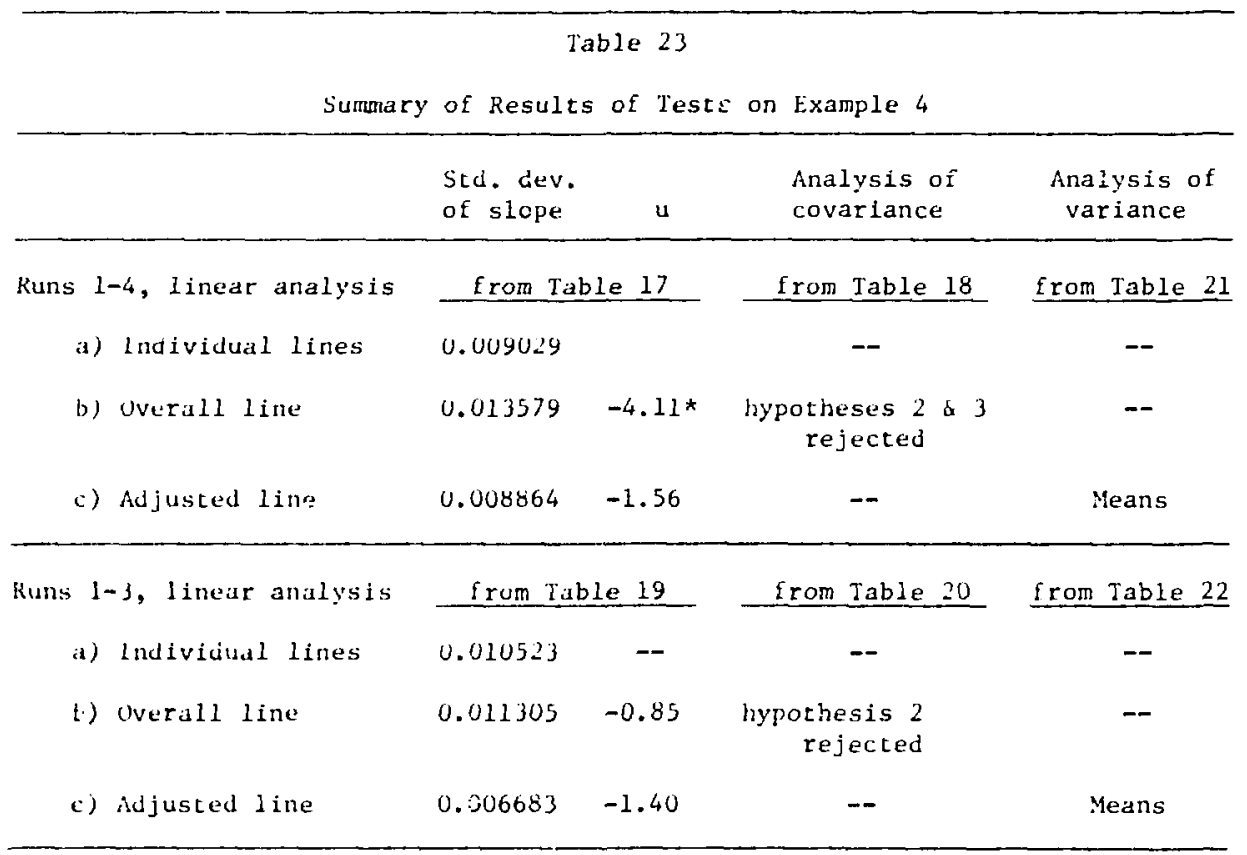

*ffypothesis of no effect was rejected. 
VI. ANALYSIS OF COVARLANCl:

The statistical notation and approach to the ant lysis of covariance used in this report are those given by Brownlee. 4 The particular formulation of the analysis of covariance of interest is that of evaluat ing the consistency between $k$ least-squares equations. By testing an ordered set of hypotheses the experimentor can determine whether or not all data points may be considered to lie on a single overall line. The notation and definitions used in the lest statistics are shown in Table 24.

The analysis of covariance involves the partitioning of the total sum of squares about the overall line into the independent component parts associated with slopes and group means that are then tested for signifiance relative to the variation due to unassignable causes. In this case the unassignable viriation represents the variance of the points about tiac individual lines.

The test of hypothesis tested is summarized in Table 25. The following hypotheses are tested:

$$
\begin{aligned}
& \mathrm{H}_{1}: \mathrm{s}_{2}{ }^{2} / \mathrm{s}_{1}{ }^{2} \text {, the least-squares equations for each of } \\
& \text { the data sets can be regarded as parallel. } \\
& \mathrm{H}_{2}: \mathrm{s}_{3}{ }^{2} / \mathrm{s}_{1}{ }^{2} \text {, the data run means }(\bar{y}, \bar{x}) \text { are not significantly different } \\
& \text { from the least-squares equation through them. } \\
& \mathrm{H}_{3}: \mathrm{s}_{4}{ }^{2} / \mathrm{s}_{1}{ }^{2} \text {, the slope, } \overline{\mathrm{b}} \text {, of the composite least-squares equation is } \\
& \text { not significantly different from the slope, } \hat{b} \text {, resulting } \\
& \text { frem } \mathrm{H}_{2} .
\end{aligned}
$$

FNo attempt is made here to develop the general method of analysis of covariance (ANOCOVA) but only to present techniques for the interpretation of such results 1.1 problems involving volume calibrations. For a romplete treatment of ANOCOVA see Chapter 11 of Brownlee. 4 
Table 24

Algebraic Notztion

\begin{tabular}{|c|c|c|}
\hline $\begin{array}{l}\text { Pt. No. } \\
j=1,2, \ldots k \\
\text { (number of runs) }\end{array}$ & $\begin{array}{c}\text { Data points } \\
i=1,2, \ldots n_{k} \\
\text { (number of points in run } k \text { ) }\end{array}$ & $\begin{array}{c}\text { Least-squares (1.s.) } \\
\text { equations* }\end{array}$ \\
\hline 1 & $\left(x_{1 i}, y_{1 i}\right)$ & $Y_{1}=\bar{y}_{1 .}+b_{1}\left(x-\bar{x}_{1 .}\right)$ \\
\hline 2 & $\left(x_{2 i}, y_{21}\right)$ & $Y_{2}=\bar{y}_{2 .}+b_{2}\left(x-\bar{x}_{2 .}\right)$ \\
\hline$\cdot$ & $\cdot$ & $\cdots$ \\
\hline j & $\left(x_{j 1}, y_{j 1}\right)$ & $Y_{j}=\bar{y}_{j .}+b_{j}\left(x-\bar{x}_{j}\right)$ \\
\hline$\cdot$ & • & $\cdots$ \\
\hline $\mathrm{k}$ & $\left(x_{k_{1}}, y_{k_{1}}\right)$ & $Y_{k}=\bar{y}_{k_{1}}+b_{k}\left(x-\bar{x}_{k_{1}}\right)$ \\
\hline
\end{tabular}

Equations from which the test statistics are derived:

\begin{tabular}{|c|c|c|}
\hline$b_{i}$ & The $k$ Individual lines & $Y=\bar{y}_{.1}+b_{1}\left(X-\bar{x}_{. i}\right)$ \\
\hline$\overline{\mathrm{b}}$ & $\begin{array}{l}\text { The } k \text { parallel lines } \\
\text { with average slope, } \bar{b}\end{array}$ & $Y=\bar{y}_{.1}+\bar{b}\left(X-\bar{x}_{.1}\right)$ \\
\hline & $\begin{array}{l}\text { The 1.s. line for the } \\
\text { group means }\left(x_{j}, y_{.1}\right)\end{array}$ & $y=\bar{y}_{\ldots} .+\hat{b}(x-\bar{x} .)$. \\
\hline & The overall 1.s. Iine & $Y=\bar{y}_{0} .+b\left(x-\bar{x}_{. .}\right)$ \\
\hline
\end{tabular}

*The conventional dot notation is used to indlcate the subscript sumed over, e.g., the symbols $\bar{x} . ., \bar{y} .$. dencte overall means. 
Table 25

Brownlee's Covariance labli

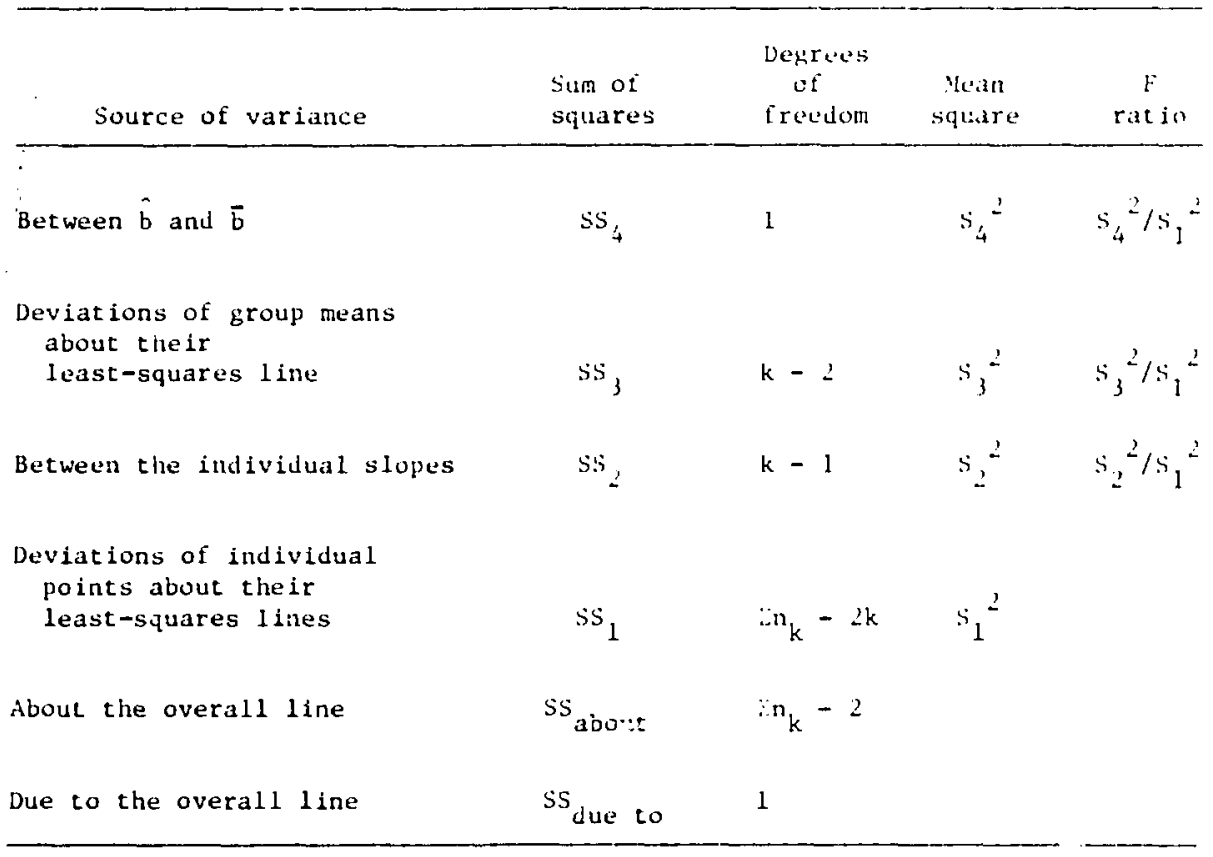


Hypothesis if should be a two-tailed test. The F ratio of ll can be sinnificantly low. A low rato indicates that the observations are all locally bound and the $k$ estimates of the incercept and slope are not independent. libe plot of the residuals of all runs on a single fiaph will usually indicate the Lause. Iwo conditions that may result in a low E ratio are (1) erratic variations due to nonlinearity of the instrument or imperfections in the lank with all calibration points falling at about the same volume measurement values, and (2) smooth changes in the cross sectional area so that a quadratic or cubic calibration equation is required. These two cases are discussed above (ixamples 2 and 3 ).

A significantly high value of $\mathrm{F}$ for the ratio $\mathrm{s}_{2}^{2} / \mathrm{s}_{1}^{2}$ indicates either that the lines are not parallel or that the pooled residual variance (s, ${ }^{2}$ ) about the individual Iines is underestimated. Comparison of the $k$ graphs of the lines may indicate which set is different. The presence of a cumulative error in the voiume measurements resulting in serial correlation will cause underestimation of the residual variance.

Hith critical $F$ values may imply that the relation between $x$ and $y$ is poorly defined. Skew lines may be caused by the lack of good calibration procedure or because of departure from the calibration procedire in one or more of the calibration runs.

The second hypothesis tested is that the $\bar{X}, \bar{y}$ points of the $k$ sets are linearly related. If the $\mathrm{F}$ ratio of $\mathrm{H}_{2}$ is significantly large this hypothesis is rejected. Probable causes of poor agreement between the data sets' means are either appreciable cunulative error in the volume measurements or variability in the tank heels. 
The third hypothesis tested is that there is no significant difference between the two slopes estimated, namely, the average slope of the $k$ lines and the slope of the linear relationship between the $k \bar{x}, \bar{y}$ points. If the $\mathrm{F}$ ratio is significantly large this hypothesis is rejected, and the plot of the residuals should be examined to determine the source. This test is strongly dependent on the magnitude of the differences between the volume measurements of the $k$ sets. If the same volume measurements are repeated in each run, the value of $\mathrm{S}_{4}^{2}$ will approach zero and the analysis of variance on adjuszed data is recommended. Example 2 above is a case of this: type.

If a hypothesis is rejected at any step of the znalysis, further testing of hypothesis should be abandoned, and the data, procedures, and calibration equipment should be examined for conditions that may result in critical $F$ values. A discussion on several conditions is given below.

When none of the hypotheses is rejected, the data may be pooled into a single overall line and $a, b, V(a), V(b)$, and covariance ( $a, b)$ calculated from the pooled data.

\section{ADJUSIMENT OF DATA AND THE ANALYSIS OF VARIANCE}

Rejection of a hypothesis in the analysis of covariance indicates that at least one of the assumptions on which the analysis is based has been violated and therefore the model assumed is not applicable. The experimenter must then formulate a new model consistent with the distribution of the observed error. In Section III, Examples 2 and 3 were used to show how adjustment of the data ind the analysis of variance might be used in the diagnosis of anomalous calibration data. Before the analysis is continued, Bartlett's test of the homogenicy of the vartance of the residuals should be made (Brownlee ${ }^{4 d}$ ). 
In appraising the characteristics of anomalous data in Section 111, values of the dependent variable were adjusted to take into account differences among the associated values of the independent variable. The average value of the volumes, $\bar{x}_{i}$, for each cluster of points was calculated, and the difference between this value and the observed value for each point $i$ and data set $j$ was used to calculate $y^{\prime}{ }_{j i}$, a new value for $y_{j i}$.

The transformation is defined by

$$
Y_{j i}=Y_{j i}-b\left(X_{j i}-\bar{x}_{i}\right)
$$

where $b=$ the overall slope defined in Table 24. A graphic illustration of the transformed data would show the $k$ values of $y^{\prime}{ }_{i}$ appearing on a line erected vertically at each $\bar{x}_{i}$.

The form of the data is now

$$
\left(\bar{x}_{i}, y^{\prime}{ }_{1 i}, y^{\prime}{ }_{2 i}, \ldots y_{k j}^{\prime}\right)
$$

In the parlance of analysis of variance, the $\bar{x}_{f}$ are treatment levels and the $y^{\prime}{ }_{j 1}$ are replicate determinations in a one-way classification. The component of variance model (Model II) is used to estimate the mean and variance for each treatment $\bar{x}_{. i}$. The model is

$$
y^{\prime}{ }_{j i}=\mu_{i}+T_{1}+\varepsilon_{j i}
$$

where

$$
\mu_{1}=\text { true magnitude of } y^{\prime}{ }_{i},
$$


$\tau_{i}=$ an effect due to the adjustment of the $y^{\prime}{ }_{i}$ at point $i$, and

$\varepsilon_{j i}=$ random measurement error common to all observations.

The term $\mu_{i}$ is constant for all measurements for a given point $i$. The term $T_{i}$ is a calculated value which is the difference, due to changes in $x_{j i}$, of the particular value $y_{j i}$ from the average of the ith point. It is assumed that each class $i$ is a sample of $k$ from a normal distribution with mean $\mu+T_{i}$ and variance $o^{2}$.

The random measurement error, $\varepsilon_{j i}$, often referred to as the experimental error, accounts for all uncontrolled effects not related to the treatments (in this case the adjustments of $\left.y^{\prime}{ }_{i}\right)$. As such, the experimental error is the combined effect of many random variables independent of the treatment effect. The $\epsilon_{j i}$ 's are assumed to be normally distributed with expected value zero and variance $\sigma_{E}^{2}$.

\section{A. Additional Discussion of Example 2}

In Example 2, abnormally low $\mathrm{F}$ ratios were observed in the analysis of covariance in testing for parallel lines or linear relationships between the means. Under these conditions the $k$ runs were considered replicates of a single calibration. This required the removal of the effect, $T_{i}$, due to differences between the volume measurements of the $k$ sets. Eq. (8) was used to adjust the data. The adjusted data for Example 2 are shown in Table 6.

In the analysis of variance the $F$ ratio for the variation of the nine group means about the line compared with the varfation of the points from the six runs about their mean was significant at $\alpha=0.001$. Thus, the variability between the six runs is much less than the error associated with the fitting of the linear least-squares 11 ne. 
A one-way analysis of varlance was made with $n$ cells each having $k-1$ degrees of freedom. The hypothesis of homogeneity of within-cell vartance was tested by Bartlett's test. Since the variances were found to be homogeneous, the within-cell variances were pooled and the variance of $\bar{y}^{\prime}{ }_{1}$ was calculated. These and other intermediate calculations are given in Table 26.

The results of the least-squares fit of $\bar{x}, \bar{y}^{\prime}$ shown in Table 4 are given in nore detail in Table 26 . The residual variance about the least-squares line should not be significantly greater than the pooled varlance of $\bar{y}$ '. However, in the case of Example 2, the standard deviation of the $\bar{y}$ residual is 0.037004 (see Table 4) and the pooled standard deviation of $\bar{y}$ is 0.001963 in Table 26. Although this still shows a significant lack of fit to a straight line, it is concluded that the model based on the adjusted data provides reasonable (i.e., correct) estimates of the variance of the slope, $V(b)$, and of the residual variance, $V(y)$.

\section{B. Additional Discussion of Example 4}

In Example 4, hypotheses 2 and 3 in the analysis of covariance were rejected because of high $F$ values in testing the four data runs. Data run 4 was then elfminated, and a second analysis of covariance was run on the remaining three data runs. Hypothesis 2 was again rejected because of a high $\mathrm{F}$ value. Although the $F$ ratio of the mean square due to differences of the individual slopes compared with the mean square of the points about their lines (hypothesis 1.) was not slgniflcantly low, the posstbillty of changes in the cross sectlonal area of the tank could not be ignored in view of the indication of considerable measurement error as evidenced by the deviation of the group means. The data for calibration runs 1 through 3 were adjusted by using Eq. (8) and were examined in a one-way analysis of variance (the discussion from 
Table 26

Computer Worksheet - Example 2

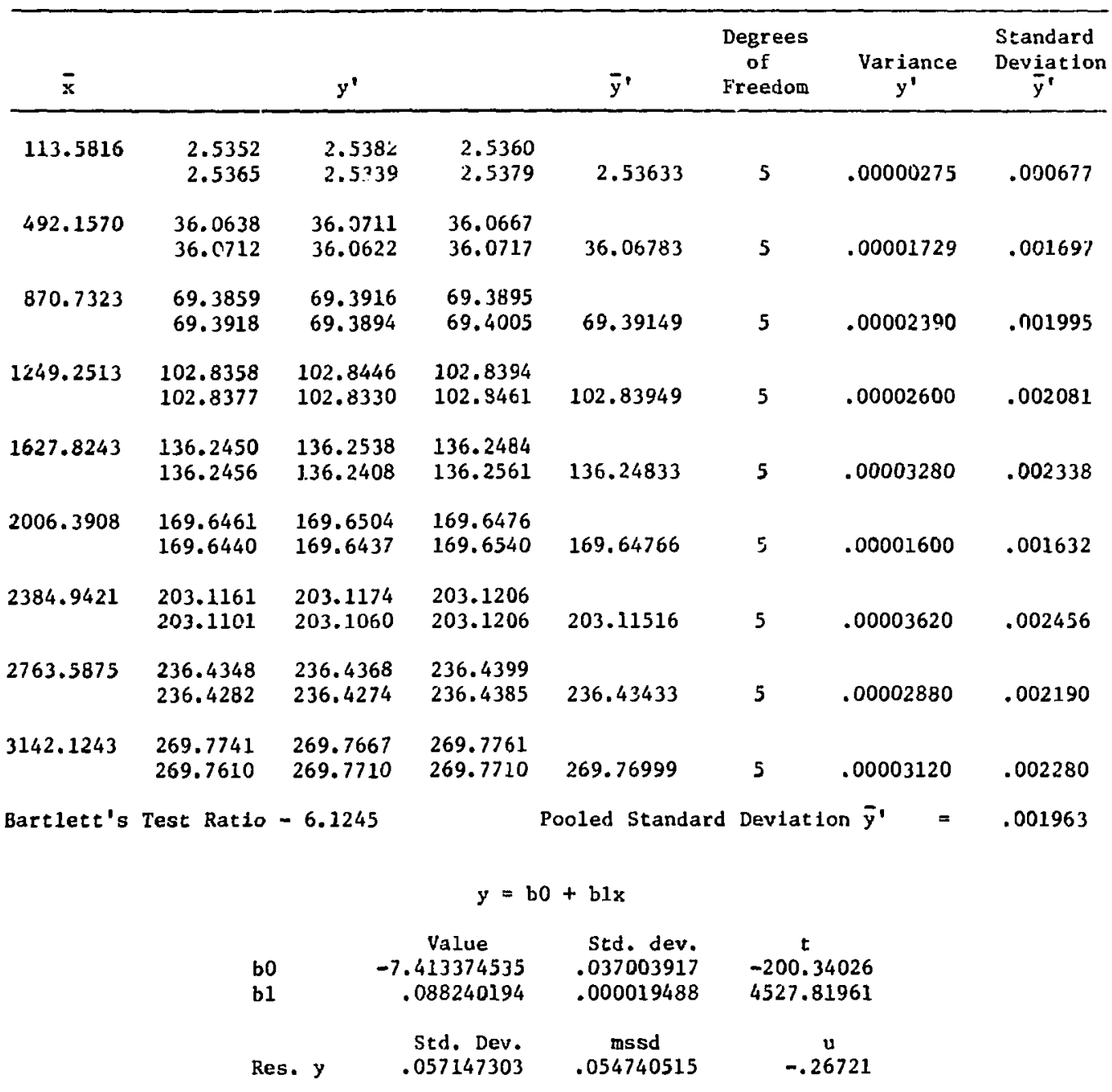




\begin{tabular}{|c|c|c|c|c|c|c|c|c|}
\hline \multicolumn{9}{|c|}{ Table 26 (cont'd) } \\
\hline Point & $\bar{x}$ & $\bar{y}$ & Pred. $\bar{y}$ & Diff. & Sum & $\mathrm{Rn}$ & Pred. $\bar{x}$ & Diff. \\
\hline 1 & 113.581 & 2.536 & 2.609 & .072 & .072 & 1.614 & 112.757 & -.824 \\
\hline 2 & 492.157 & 36.067 & 36.014 & -.053 & .019 & 1.082 & 492.759 & .602 \\
\hline 3 & 870.732 & 69.391 & 69.420 & .028 & .048 & .554 & 870.406 & -.325 \\
\hline 4 & 1249.251 & 102.839 & 102.820 & -.018 & .029 & .350 & 1249.463 & .211 \\
\hline 5 & 1627.824 & 136.248 & 136.226 & -.022 & .007 & .411 & 1628.075 & .251 \\
\hline 6 & 2006.390 & 169.647 & 169.630 & -.016 & -.009 & .313 & 2006.580 & .189 \\
\hline 7 & 2384.942 & 203.115 & 203.034 & -.080 & -.790 & 1.558 & 2385.857 & .915 \\
\hline 8 & 2763.587 & 236.434 & 236.446 & .011 & -.078 & .240 & 2763.453 & -.133 \\
\hline 9 & 3142.124 & 269.770 & 269.848 & .078 & .000 & 1.736 & 3141.237 & -.887 \\
\hline
\end{tabular}


here on relates to data with run 4 deleted). The adjusted data for Example 4 and the results of the analysis of variance are presented in Table 27 , which shows the twelve $\bar{x}, \bar{y}$ ' points and the least-squares fit. The observed standard deviation of the twelve $\bar{x}, \bar{y}^{\prime}$ points about their least-squares line $(0.018473)$ is smaller than the observed standard deviation of $\bar{y}^{\prime}(0.035485)$, which indicates that the effect due to changes in the cross sectional area of the tank is negligible. In Example 4 an effect was observed that is the opposite of that in Example 2: the pooled standard deviation of the average $y^{\prime}$ is greater than the standard deviation of the $\bar{y}$ residuals. In Example 2 the major error source is in the departure of the data from a straight line; in Example 4 the major error source is in the $y$ data.

The conclusion drawn regarding these calibration data is that the major source of error is in the menometer measurements. In particular, it afpears that the sensitivity of the manometer is the limfting feature of the measurement system. The least-squares fit of the individual data points for the overall line is judged to provide a less valid estimate of the variance of the slope than the least-squares fit of the twelve $\bar{x}, \bar{y}$, points (adjusted data).

\section{MEAN-SQUARE SUCCESSIVE, DIFFERENCE}

If the least-squares model for fitting the data is correct, the residuals will be randomly distributed about a mean of zero. The lack of randomness of the residuals is a strong indication that the data were fitted by an incorrect method. The mean-square successive difference ( $u$ ) test is sensitive in many instances to nonrandom fluctuations. In particular, it is sensitive in detecting serial correlations and trends, either periodic or otherwise. The statistic 
Table 27

Computer Worksheet - Example 4 for $k=3$

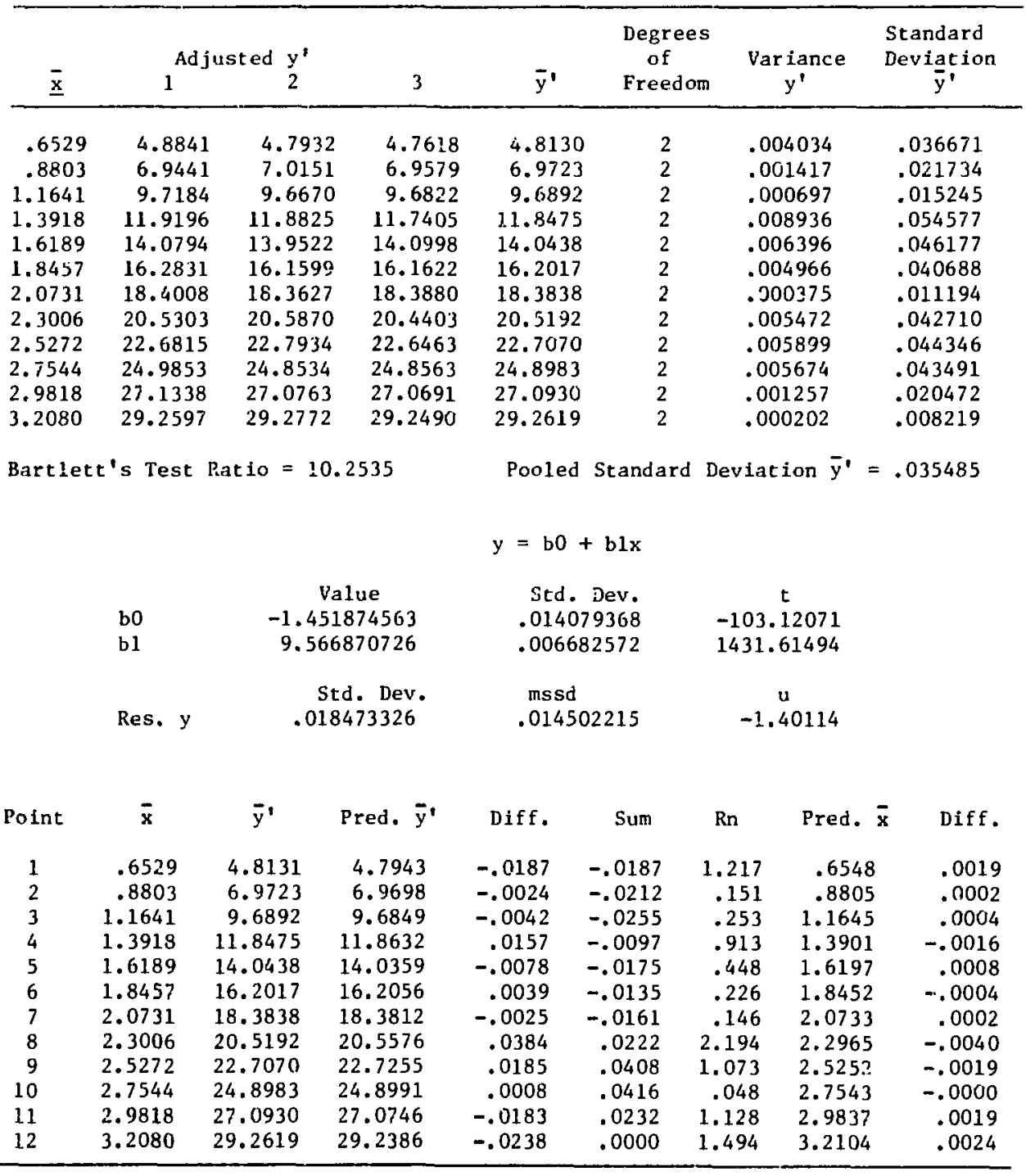


is obtained by first calculating $d^{2}$, the mean of the squares of the $n-1$ successive differences between the residuals, $R_{1}$ :*

$$
d^{2}=\frac{\Sigma\left(R_{i+1}-R_{1}\right)^{2}}{n-2}
$$

where

$$
\begin{aligned}
& R_{i}=\left(y_{i}-\hat{y}_{i}\right), \\
& y_{i}=\text { observed } y, \text { and } \\
& \hat{y}_{i}=\text { predicted } y .
\end{aligned}
$$

The $d^{2} / 2$ is compared with estimated variance about the least-squares 1ine, $s^{2}$ :

$$
s^{2}=\sum R_{i}^{2} /(n-2)
$$

The test statistic, $u$, is defined by

$$
u=\left[\frac{d^{2}}{2 s^{2}}-1\right] /\left[\frac{n-3}{(n-1)^{2}-1}\right]^{1 / 2},
$$

and $u$ is approximately normally distributed with mean zero and unit standard deviation.

The test of randomness is based on the agreement (or disparity) between $d^{2} / 2$ and $s^{2}$. In the case of long trends the ratio $d^{2} / 2 s^{2}$ will be less than one since the value of $d^{2} / 2$ will not be increased by the trend to as great an extent

*The degrees of freedom that form the denominator in the equations defining $\mathrm{d}^{2}$ and $u$ for $n$ values of observed data are $n-1.4 \mathrm{c}$ For use of these equations on residual data, $\mathrm{n}$ is replaced by $\mathrm{n}-1$ in Eqs. (11) to (13). 
as $s^{2}$. For short oscillations both $d^{2} / 2$ and $s$ will increase, but the increase in $\mathrm{d}^{2} / 2$ will usually be proportionally larger.

Long trends are associated with high negative values of $u(u \leq-2)$ and short oscillations with high positive values $(u \geq 2)$. Thus, high negative values of $u$ indicate that the dominant error is due either to serial correlation (Example 1) or to changes in the cross sectional area of the tank (Examples 2 and 3). High positıve values of u indicate that the dominant error is in the $y$ variate, which may be due to manometer reading error.

A. Additional Discussion of Example 3

The data in Example 3 were judged to be cubic rather than quadratic. The plot of the overall quadratic line is shown in Figure 7. From visual comparison of this with the cubic line (ligure 5), it is difficult to determine whether the cubic provides a significant improvement, but the $F$ test (Table 12) indicates that it does.

The mean-square successive differences, u values, for all these data sets in Example 3 were $<-2$, and are sumparized in Table 9 . This test and inspection of Figures 4, 5, and 7 identified the major error as being due to changes in the cross sectional area of the tank. Because the $u$ test is applied to data within individual runs, the degrees of freedom will always be fewer than in tests based on combined run data, and hence it is a less sensitive test.

\section{SUMMARY}

The calibration model is

$$
y+e_{y}=a+b \Sigma\left(x+e_{x}\right)+e_{t}
$$




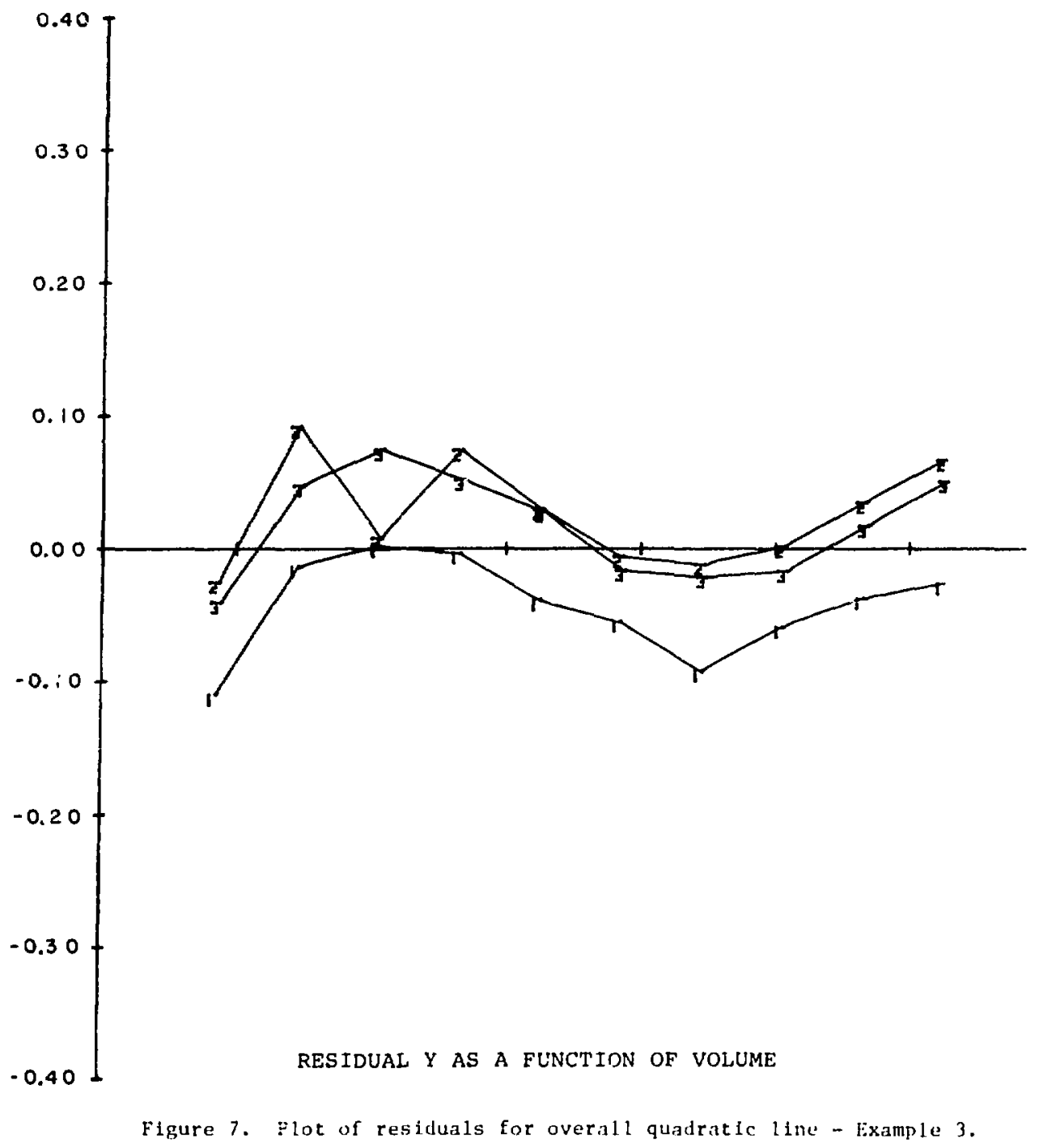


where $a$ and $b$ are the intercept and slope, respectively, and

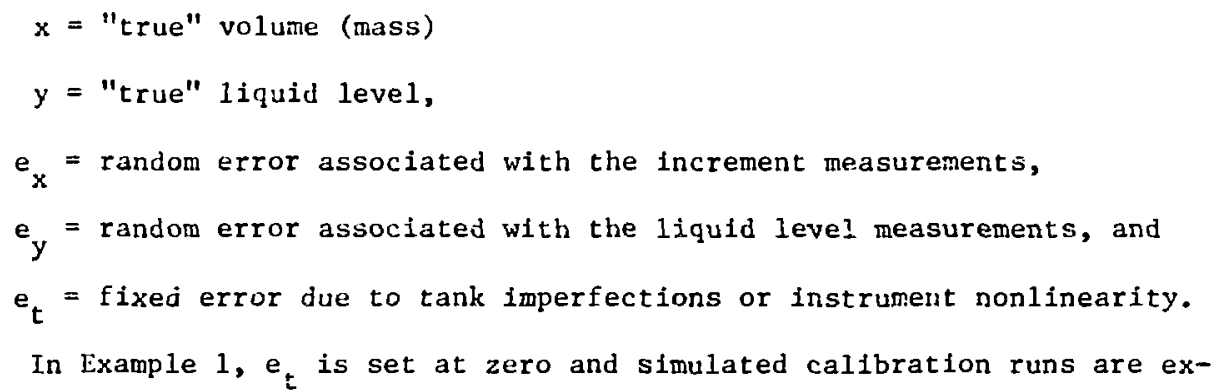

The typlcal standard deviation on a 100-1iter precision prover is 0.0075 liters and for an electromanometer, 0.02 centimeters. It is shown that if a precision prover and an electromanometer are used, the independent error model is permitted, with negligible effect due to underestimation of the variance of the slope. The examination of process data suggests that many other factors are more troublesome and will normally present a greater challenge to the analyst. The plotting and close examination of the residual y data was found to be the single most useful thing an anaiyst can do. In this report it is shown how six different statistical tests can be applied to the calibration data. These tests are important and are an integral part of the analysis, but they seldom reveal why a hypothesis is rejected or what would be a useful next step in the analysis. This information is usually provided in the plot of the $y$ residuals, The statistical tests on the fit of the Independent error model to the data are as follows:

1. The $R_{n}$ test for detection of a single outlier.

2. The u test for serial correlations and trends. 
? The analysis of covariance for the comparison of several linear equations.

4. Bartlett's test for homogenlety of the variance of the residuals.

5. One-way analysis of variance on the adjusted data.

6. Cross-classification model of the analysts of varlance to rest run versus data point effects.

In addition, the method of orthogonal polynomials is used to fit equations of higher degree where the data warrant.

Example 2 provides an almost classic example of the case in which $e_{t}$ is the major source of error. The example is used to introduce the technique for adjusting data. The method is discussed at length in Section VII. This technique depends on having the points clustered, $i, e .$, repeating the points in succeeding runs. This was a useful exercise in every one of the examples studied in this zeport. The condition of having the data points repeated as closely as possible in succeeding runs is contrary to the procedure suggested in ANSI $N 15.19 .9$

On the basis of the examples studied in this report and other data, it is conjectured that very few tanks are perfect. In general, the analyst will need all the ingenulty and resourcefulness he can muster for the analysis of calibration data, and he should be prepared to make compromises for nonuniformity of the tank. That is, the residuals will not display a nice random pattern in such a case; however, this does not invalidate the result of the linear least-squares fit.

If the tank is nonunfform and many data points are taken, one can be assured that a test on runs of residual values of like sign will be statistically significant as will all tests based on the assumption of random error. 
lixample 2 also illustrates the case of an overabundance of runs and not enough points. If the principle source of error is the nonunfformity of the tank, additional points would help to plot the tank's profile. If points are being repeated, as they were here, small advantage is gained by having more than four runs.

In Example 3, the opposite effect is seen. The number of points is more than adequate but an additional run would have been helpful. It is possible that too many calibration points can result in underestimation of the variance of the slope.

In Example 3, the lack of fit of the linear least-squares line due to large $e_{t}$ errors is examined. A cubic equation is used to eliminate the $e_{t}$ effect.

The effects of the presence of all three error terms on a linear calibration equation are illustrated in Example 4.

Having established the principal source of error, the analyst must then decide how to treat the data in such a way that the final product is an acceptable calibration curve. At this stage it is beneficial to know how the tank is to be used and the required degree of accuracy. It may often be possible to accept the adjusted line as in Example 2 even though the line is not a perfect fit. Often, it need not be a perfect fit, but it should be sufficient for the intended use.

The techniques emphasized in this report are not intended to give minimum variance of the slope. The objective is to determine the variance that best describes the actual variability associated with the measurements made, on the basis of the calibration curve. The goal here is to obtain an estimate of the 
variance of the slope such that the linft of error on the measurements truly reflects the uncertainty in the data.

\section{REFERENCES}

1. Jaech, John L., Statistical Methods in Nuclear Material Control, pp. 120-36, TID 26298, UPO, Washington, D. C., 1973.

2. Mande1, John, The Statistical Analysis of Experimental Data, (a) pp. 308-9, (b) Pp. 295-303, Wiley-Interscience, New York, 1964.

3. Natre1la, M. G., Experimental Statistics, (a) p. T-86, (b) p. 6.2, NBS Handbook 91, GPO, Washington, D. C., 1963.

4. Brownlee, K. A., Statistical Methodology in Science and Engineering, 2nd ed., (a) pp. 329-43, (3) pp. 366-76, (c) p. 221, (d) pp. 292-3, Wiley, New York, 1965.

5. Schooner, R. M. and Houser, J. F., Pressure Type Liquid Level Gauges, p. 22, NBS Internal Report 10396 , GPO, Washington, D. C., 1970.

6. Tietjen, G. L., Moore, R. H., and Beckman, R. J., Testing for a single outlier in simple linear regression, Technometries 15, No. 4, 717-21 (1973).

7. Wilson, D. W., Private communications, 1974.

8. Anderson, L. G., Private communications, 1974.

9. American National Standard Volume Calibration Techniques for Nuclear Materials Control, N15.19 - 1975. 